\title{
Detecting Land Cover Change at the Jornada Experimental Range, New Mexico with ASTER Emissivities
}

\author{
A. N. French \\ U.S. Arid Land Agricultural Research Center, USDA/ARS, 21881 N. Cardon \\ Lane, Maricopa, AZ 85238 USA \\ T. J. Schmugge
}

Gerald Thomas Professor of Water Resources, College of Agriculture, New Mexico State University, Las Cruces, NM 88003, USA

J. C. Ritchie

USDA/ARS Hydrology and Remote Sensing Laboratory, Beltsville, MD 20705, $U S A$

A. $\mathrm{Hsu}$

USDA/ARS Hydrology and Remote Sensing Laboratory, Beltsville, MD 20705, USA

F. Jacob

Institute of Research for the Development, Laboratory for studies on Interactions between Soils-Agrosystems-Hydrosystems, UMR LISAH SupAgro/INRA/IRD, 
Montpellier, France; formerly at Remote Sensing and Land Management

Laboratory, Purpan Graduate School of Agriculture, Toulouse, France

K. Ogawa

Defense Systems Group, Hitachi Ltd., Tokyo, Japan

\begin{abstract}
Multispectral thermal infrared remote sensing of surface emissivities can detect and monitor long term land vegetation cover changes over arid regions. The technique is based on the link between spectral emissivities within the 8.5-9.5 $\mu \mathrm{m}$ interval and density of sparsely covered terrains. The link exists regardless of plant color, which means that it is often possible to distinguish bare soils from senescent and nongreen vegetation. This capability is typically not feasible with vegetation indices. The method is demonstrated and verified using ASTER remote sensing observations between 2001 and 2003 over the Jornada Experimental Range, a semi-arid site in southern New Mexico, USA. A compilation of 27 nearly cloud-free, multispectral thermal infrared scenes revealed spatially coherent patterns of spectral emissivities decreasing at rates on the order of $3 \%$ per year with $\mathrm{R}^{2}$ values of $\sim 0.82$. These patterns are interpreted as regions of decreased vegetation densities, a view supported by ground-based leaf area index transect data. The multi-year trend revealed by ASTER's 90-m resolution data are independently confirmed by 1-km data from Terra MODIS. Comparable NDVI images do not detect the long-term spatially coherent changes in vegetation. These results show that multispectral thermal infrared data, used in conjunction with visible and near infrared data, could be particularly valuable for monitoring land cover changes.
\end{abstract}

Email address: Andrew.French@ARS.USDA.GOV (A. N. French). 


\section{Introduction}

Monitoring the spatial and temporal changes in land cover for semi-arid and arid land regions is required for hydrologists, ecologists, and agronomists. Land cover information is used by hydrologists to update surface conditions affecting stream flow, infiltration, and evapotranspiration (Menenti et al. 2005, Su 2000); by agronomists for acreage and yield prediction (Fang 1998); and by ecologists for assessing the relationships between land degradation, human activities, and global climate change (Chehbouni et al. 2000). The need for this monitoring is especially important in dry regions, since many of these are productive agricultural lands under pressure from extreme drought and population increase (Falkenmark 1997).

Land cover change has been documented for decades over critical semi-arid regions, such as West Africa (Diouf and Lambin 2001), the Mediterranean Basin (Sobrino et al. 2001), and for more than 100 years, southern New Mexico, USA (Buffington and Herbel 1965). In the latter instance, observations have revealed large and deleterious changes where rangeland previously dominated by grass has become dominated by mesquite and creosotebush (Gibbens et al. 2006, Havstad et al. 2000).

The significance of these long-term observations, though previously recognized, has only begun to be fully appreciated by the use of remotely sensed data spanning multiple decades (Rango et al. 2005). Using frequent synoptic remote sensing observations of arid lands, especially if they were available at resolutions better than $100 \mathrm{~m}$, would greatly improve our ability to monitor, analyze, and understand the implications of rapid land cover changes. 
A common approach to monitoring land cover change compatible with the objective of long term monitoring is to collect well-calibrated vegetation index (VI) data [e.g., the normalized difference vegetation index (NDVI) and its variants]. These observations are now routinely collected at daily to bi-weekly temporal sampling and at spatial resolutions between $1 \mathrm{~m}$ and $1 \mathrm{~km}$ from sensors such as Ikonos (Dial et al. 2003), Advanced Spaceborne Thermal and Reflection radiometer (ASTER) (Yamaguchi et al. 1998), Landsat (Goward et al. 2001), the Vegetation instruments aboard Satellites Pour l'Observation de la Terre (SPOT4 and SPOT5), and MOderate-resolution Imaging Spectrometer (MODIS) (Justice and Townshend 2002, Justice et al. 1998), each of which provides useful estimates of living, green vegetation. The relationship between vegetation indices and fractional cover and leaf area indices has been widely investigated (e.g., Gutman and Ignatov 1998, Choudhury 1987, Baret et al. 1995, Carlson and Ripley 1997, Jiang et al. 2006), meaning that accurate and reliable estimates of green biomass are usually obtainable from remote sensing platforms, provided ancillary data about observational conditions and expected plant cover types are also available. Based on these established relationships, time series of VI data have been used to detect both seasonal and yearly land cover changes (Wardlow et al. 2007, Telesca and Lasaponara 2006, Anyamba and Eastman 1996, Justice et al. 1986, Byrne et al. 1980).

Although the vegetation index approach has demonstrated its value for land cover change monitoring, it has a frequently unmentioned shortcoming - during plant dormancy, VI values are similar to and possibly indistinguishable from bare soils. Even for indices specifically designed to minimize soil background effects, such as the Modified Soil Adjusted Vegetation Index (MSAVI) (Qi et al. 1994), the spectral inputs from red and near infrared wavelengths 
do not readily distinguish soils from non-green vegetation. In instances where the landscape is bare soil, the VI maps are likely representative of true conditions. But for other instances where the above-ground biomass remains during winter months and is senescent or inactive, the resultant VI maps are not representative. For much of the year in arid lands, living plants are non-green; and discriminating them from soil, using indices such as NDVI, is difficult. When assessing vegetation cover changes over a period of years, the difficulty is particularly significant because within-season VI variability is just as large, or larger than, interannual VI variability. The difficulty is exacerbated by an inability to obtain frequent remote sensing images because of cloud cover (e.g., from Landsat) or because the spatial resolution is too coarse for areas of interest (e.g., from MODIS). Unless one can be confident that VI extremes within a plant growth cycle are captured, postulated VI trends will be biased by insufficient temporal sampling. Hence, use of VI methods to infer rates of land cover change over sparsely vegetated landscapes can be misleading.

More recent work indicates VI can be improved by incorporation of hyperspectral near infrared (NIR) data, such as in the $2.2 \mu \mathrm{m}$ region, where cellulose and lignin absorption features appear (Bannari et al. 2006, Daughtry et al. 2005). In these ongoing studies, good discrimination between soil and vegetation appear possible using end-member analyses.

When evaluating land cover over months to years, an alternative monitoring approach does exist and is based upon spatial estimation of thermal infrared emissivities. Emissivity $\left(\epsilon_{\lambda}\right)$, a measure of thermal radiation efficiency, is defined as the ratio between actual emitted radiation $\left(\mathrm{L}_{\lambda}\right)$ and emitted radiation 
from a blackbody $\left(\mathrm{L}_{\lambda, \mathrm{BB}}\right)$ at the same temperature:

$$
\epsilon_{\lambda}=\frac{\mathrm{L}_{\lambda}}{\mathrm{L}_{\lambda, \mathrm{BB}}}
$$

Emissivity is the proportionality factor that distinguishes brightness temperatures from true radiometric temperatures (Norman and Becker 1995) and is important for modeling the earth's surface energy balance. The energy balance at long wavelengths also plays a role in the ability to observe land surface emissivities:

$$
\mathrm{L}_{\text {sensor }}=\epsilon \mathrm{L}_{\text {surface }}+(1-\epsilon) \mathrm{L} \downarrow
$$

where thermal infrared radiation (TIR) observed by a sensor $\left(\mathrm{L}_{\text {sensor }}\right)$ just above the surface is the weighted sum of band surface emitted radiation $\left(\mathrm{L}_{\text {surface }}\right)$ and band downwelling sky radiation $(\mathrm{L} \downarrow)$. Band-averaged emissivity $(\epsilon)$ and its complement are the weighting factors, which means that estimation of surface emissivity is only possible when contrast exists between $\mathrm{L}_{\text {surface }}$ and $\mathrm{L} \downarrow$. Emissivity is independent of temperature itself and varies spectrally according to surface composition and geometry. These latter properties make emissivity observations potentially useful for land cover characterization. Measurements at laboratory scales (Salisbury and D'Aria 1992, Elvidge 1988), for example, show that emissivities of soil and vegetation are commonly distinct and do not rely upon plant chlorophyll content. This makes emissivity a potential tool for discriminating soil and vegetation emissivities. At field scales, soil and vegetation can still be distinguished (Humes et al. 1994), as illustrated by observations of senescent vegetation during a 1997 study over Oklahoma (French et al. 2000). In that instance, emissivities at wavelengths between 8 and $9.5 \mu \mathrm{m}$ were close to 1.0 for vegetation, while those for soils were $\sim 0.91$. 
Considering the capabilities of VI and emissivity data together, a three-way characterization of land cover is possible by distinguishing bare soils, green vegetation, and non-green vegetation.

Since 2000 an important remote sensing capability became available through the launch of the ASTER instrument in December 1999 onboard the Terra satellite. ASTER uniquely offers multispectral thermal infrared (TIR) remote sensing at moderate resolution $(90 \mathrm{~m})$, data unavailable elsewhere. Using ASTER's five thermal bands, land surface emissivities could be estimated in ways similar to that used by French et al. (2000) for the Oklahoma study, allowing more extensive evaluation of the land cover discrimination approach.

One such evaluation arose fortuitously from ongoing studies of a semi-arid rangeland in southern New Mexico, USA, at a research site utilizing remote sensing image data to monitor landscape structural evolution and land surfaceatmosphere exchanges. The study site, known as the Jornada Experimental Range (Jornada), has been the focus of local and regional remote sensing studies since 1995. The primary theme of these studies is assessment of rangeland health, including that of vegetation land cover changes.

Vegetation cover changes at Jornada have been dramatic and occur over a wide range of time scales. Using surveys from 1858, Gibbens et al. (2006) document the transformation of the rangeland from a productive grassland to a degraded landscape dominated by shrubs in 1998. Over this 140 year span, grassland decreased from $67-98 \%$ coverage to less than $1 \%$. Recent Jornada studies (e.g., Snyder and Tartowski 2006) suggest too that significant vegetation changes occur at much shorter time spans, particularly at seasonal to annual scales where vegetation patterns change in complex ways in response 
to highly variable water availability.

The importance of Jornada for this study is that vegetation cover changes in this area have occurred at observable time scales and that related ground observations may be available to help validate changes inferred from remotely sensed emissivities. Using ASTER data over 2001-2003, consisting of 27 nearly cloud-free scenes, emissivity trends can be analyzed and compared with independently obtained observations.

Analysis and comparisons proceed in six main steps. First, emissivity retrieval approaches from the multispectral thermal infrared sensor ASTER are considered. Three different techniques are described and implemented. This is done because consensus is lacking for optimal temperature-emissivity separation and because of concerns that inferred emissivity changes could be data processing artifacts. Second, information about the Jornada setting is discussed. In the third step (the study focus) emissivity changes observed over Jornada are described, with particular attention paid to anomalously large changes indicative of vegetation land cover degradation. In the fourth step the significance of the changes is considered. Here tests are employed to determine the importance of interfering effects upon emissivity retrieval precision and bias. Fifth, an important related issue is addressed, namely the relationship between vegetation cover and thermal emissivities. Frequently emissivity data are estimated from VI's, an approach that effectively questions the utility of emissivity observations. Here the non-equivalence of remotely sensed VI's and emissivities are shown. Sixth, the overall significance of the ASTER-Jornada study is discussed, and ASTER emissivity patterns are interpreted. 


\section{Remote Sensing Estimation of Emissivity}

A major benefit of multispectral thermal infrared remote sensing is its ability to estimate land surface temperatures, spectral emissivities, and broadband emissivities within the TIR window. These properties are especially valuable when observed simultaneously because they help achieve land surface temperature (LST) accuracies better than $1{ }^{\circ} \mathrm{C}$ and help distinguish between different land surfaces according to soil, rock and vegetation cover (Tonooka 2001, Gillespie et al. 1998, Hook et al. 1992, 2001). By contrast, spectral emissivity characterization is not feasible with single-window TIR, nor with most dual-window TIR instruments. Although it is true that multiple bands also cannot resolve the under-determined TIR remote sensing problem (i.e., that for $\mathrm{N}$ bands, there exist $\mathrm{N}+1$ unknowns, namely $\mathrm{N}$ emissivities plus one surface temperature), they do allow objective characterization of the emissivity spectrum, an accomplishment otherwise infeasible. This makes it possible to relate spectral variations to surface composition and surface cover, as well as help improve atmospheric corrections (Tonooka 2001).

Various approaches to estimating emissivity from multi-band TIR data exist, examples of which are discussed in Jiménez-Muñoz et al. (2006), Jacob et al. (2007), Dash et al. (2002), and Li et al. (1999). Analyses considered in this study were the Temperature-Emissivity Separation (TES, Gillespie et al. 1998) approach, the Temperature-Independent Spectral Indices (TISI, Becker and Li 1990) approach, and the Normalized Emissivity Method (NEM, Gillespie 1985, Kahle and Alley 1992, Kahle et al. 1980) approach. For reasons discussed below, the primary approach used for the Jornada study was NEM. However, TES and TISI were also employed to demonstrate that results 
from the land cover change assessment were not contingent upon the choice of algorithm.

One of the better-known temperature and emissivity algorithms for ASTER images is TES, a procedure that resolves the under-determinacy ${ }^{1}$ by employing an empirical functional relationship between emissivity spectral contrast and minimum emissivity (Matsunaga 1994). With TES the minimum emissivity $\left(\epsilon_{\min }\right)$ of a sample can be closely approximated by estimating the range of either absolute or relative emissivities $(\Delta \epsilon)$ via the formula:

$$
\epsilon_{\min }=\mathrm{b}_{0}+\mathrm{b}_{1} \Delta \epsilon^{\mathrm{b}_{2}}
$$

where parameters $b_{0}, b_{1}$, and $b_{2}$ are derived from laboratory measurements of emissivities. For standard ASTER data products, the parameters are based on over 200 laboratory samples. For this study, the parameters used were 0.994, -0.687, and 0.737, respectively. By iteratively combining Eq. 3 with atmospherically corrected surface emitted radiance for each thermal band, the radiometric surface temperature can be separated from emissivities for each TIR band.

Based on simulation studies, Gillespie et al. (1998) show that accuracies of $\pm 1.5^{\circ} \mathrm{C}$ and \pm 0.015 in emissivities are possible with TES. Recent experience with ASTER and TES generally confirms this assessment, particularly for geological applications, where emissivity contrasts are large (Tonooka 2001,

$\overline{1}$ The under-determination can also be resolved with multiple observations, as is done in the day-night method (Watson 1992). That method however is highly sensitive to measurement errors, atmospheric correction errors, and co-registration of images (Mushkin et al. 2005). 
Rowan et al. 2005, Rowan and Mars 2003, Hook et al. 2005).

Due to the method's complexity, readers interested in TES implementation details should consult Gillespie et al. (1998) and the ASTER Theoretical Basis Document for the standard data product AST05. ${ }^{2}$

For agricultural applications the TES procedure is less satisfactory because the land surfaces are dominated by high emissivities. In these cases, TES's differencing approach tends to under-estimate emissivities and consequently overestimate land surface temperatures, particularly over gray body targets such as vegetation (Jacob et al. 2004). Potential emissivity errors can exceed $2.0 \%$, resulting in errors of $2-3^{\circ} \mathrm{C}$. This outcome is a consequence of the method's inability to distinguish between true and apparent spectral contrast, where the latter can be due to signal noise or inaccurate atmospheric compensation. Improving temperature and emissivity retrievals for studies therefore requires alternatives to ensure that high emissivity targets remain so after the temperature-emissivity separation.

One way to achieve such a result is to utilize the normalized emissivity method (NEM, Gillespie 1985, Kahle and Alley 1992), an initialization procedure for TES. NEM is straightforward: a maximum spectral emissivity $\epsilon_{\max }$ appropriate for the scene (0.98 is used for this Jornada study) is specified for whichever band has the maximum surface brightness temperature. Commonly this maximum temperature appears in bands sampling wavelengths between 10 and $13 \mu \mathrm{m}$. Once identified, the radiometric surface temperature at that band is computed, then applied to the remaining TIR bands to extract spectral emis-

$\overline{2}$ Available at: http://eospso.gsfc.nasa.gov/eos_homepage/for_scientists/atbd/docs/ASTER/atbd-ast-05-08.pdf 
sivities.

The NEM approach of pre-specifying $\epsilon_{\max }$ is not an arbitrary one and requires some judgment based on landscape context and targets of interest (Kahle and Alley 1992). Pre-specification has a direct effect upon emissivity retrieval, where consistent selection of $\epsilon_{\max }$ allows meaningful relative comparisons of emissivities between different scenes but may cause substantial differences with respect to other temperature-emissivity separation techniques. Since $\epsilon_{\max }$ is close to 1.0, sensitivity to its pre-specification is small when accounting for downwelling sky radiation (last term in Eq. 2). Nerry et al. (1998) show that the impact of assuming an initial emissivity while computing a downwelling radiation correction term was small, $\leq 0.14 \%$. Dash et al. (2005) found yet smaller uncertainties. For combined soil and vegetated terrain, band averaged maximum emissivities are commonly within $1.5 \%$ of 0.98 . Considering soil emissivity spectra from the Johns Hopkins collection within the ASTER spectral library (Salisbury and D'Aria 1992, Jet Propulsion Laboratory 2001), 39 of 41 samples $(95 \%)$ had $\epsilon_{\max }>=0.965$ somewhere in the TIR window. For this library set, 38 of the 41 had the maximum emissivity located in either ASTER band 13 or $14(10.25-11.65 \mu \mathrm{m})$, while 3 were associated with the shorter wavelength ASTER band $10(8.125-8.475 \mu \mathrm{m})$. No maximum values were found in ASTER bands 11 or 12 (respectively, 8.475-8.825 and 8.925$9.275 \mu \mathrm{m}$ ). At more typical remote sensing scales (e.g., $90 \mathrm{~m}$ for ASTER), vegetation is viewed as a canopy rather than as individual leaves and multiscattering effects would increase maximum emissivities to over 0.99 and reduce the variability of maximum emissivities (Fuchs and Tanner 1966, 1968, Sutherland and Bartholic 1977, Norman et al. 1995, Palluconi et al. 1990, Zhang and Smith 1990). 
Table 1

Power function parameters for ASTER TIR bands according to: $\mathrm{L}=\alpha \mathrm{T}^{\mathrm{n}}$, with spectral radiance $\mathrm{L}\left(\mathrm{mW} \mathrm{m}^{-2} \mathrm{sr}^{-1} \mu \mathrm{m}^{-1}\right)$ and temperature $(\mathrm{K}) \cdot \bar{\lambda}$ is the band's central wavelength $(\mu \mathrm{m})$.

\begin{tabular}{cccc}
\hline Band & $\bar{\lambda}$ & $\alpha$ & $\mathrm{n}$ \\
\hline 10 & 8.2819 & $1.7825739 \mathrm{e}-10$ & 5.5393314 \\
11 & 8.6313 & $6.2117374 \mathrm{e}-10$ & 5.3234390 \\
12 & 9.0757 & $2.6602331 \mathrm{e}-9$ & 5.0742792 \\
13 & 10.650 & $1.5377459 \mathrm{e}-7$ & 4.3605276 \\
14 & 11.2812 & $5.4625771 \mathrm{e}-7$ & 4.1325621 \\
\hline
\end{tabular}

Another method that can overcome the low $\epsilon_{\max }$ problem is TISI (Becker and $\mathrm{Li}$ 1990), a technique that computes relative emissivities $\left(T I S I_{i, j}\right)$ from power-scaled brightness temperatures:

$$
\operatorname{TISI} I_{i, j}=\left[\frac{\mathrm{T}_{i}}{\mathrm{~T}_{j}}\right]^{\mathrm{n}_{i}}
$$

where $\mathrm{T}_{i}$ and $\mathrm{T}_{j}$ are atmospherically corrected brightness temperatures for spectral channels $i$ and $j$. The exponent $\mathrm{n}_{i}$ can be determined from a least squares analysis:

$$
\mathrm{L}_{\mathrm{i}} \sim \alpha_{\mathrm{i}} \mathrm{T}_{\mathrm{i}}^{\mathrm{n}_{\mathrm{i}}}
$$

where channel spectral radiance is $\mathrm{L}_{\mathrm{i}}\left(\mathrm{mW} \mathrm{m}^{-2} \mathrm{sr}^{-1} \mu \mathrm{m}^{-1}\right)$ and radiometric temperature for a channel is $\mathrm{T}_{\mathrm{i}}(\mathrm{K})$.

Table 1 lists the best-fit terms for Eq. 5, considering ASTER channels 10-14. TISI values are nearly independent of land surface temperature, which means that their uncertainties can potentially be low, given accurate atmospheric corrections. However, TISI values are non-unique, dependent upon the chosen 
bands, and indicate emissivity ratios, as discussed by Becker and Li (1990). To retrieve emissivities themselves, further observations or additional assumptions are needed. In the former case, nighttime shortwave infrared data are suitable (Petitcolin and Vermote 2002), but in this study, such data at $90 \mathrm{~m}$ spatial scales are not available. In the latter case, a reference channel emissivity can be used in the same way as for the NEM approach .

In summary, remote sensing estimation of emissivity at Jornada can be achieved in several ways, three of which are considered here. None can be accomplished in the current context without underlying assumptions. These include assumptions about spectral emissivity contrast and the existence of an accurate emissivity reference channel.

\section{The Jornada Experiment}

The Jornada Experimental Range (Jornada) research area is a semi-arid rangeland in southern New Mexico, $30 \mathrm{~km}$ northeast of the city of Las Cruces and $40 \mathrm{~km}$ west of White Sands (Fig. 1). The core study sites are within the Jornada Experimental Range, a US Department of Agriculture research site since 1912 to study effective management of grazingland. Jornada is also a Long Term Ecological Research (LTER) site (http://jornada-www.nmsu.edu), a collaborative research program established by the National Science Foundation in 1980 to support research on long-term ecological phenomena in the United States (http://lternet.edu/). South of Jornada is the New Mexico State University Ranch, also known as the Chihuahuan Desert Rangeland Research Center (http://spectre.nmsu.edu/dept/welcome.html?t=cdrr). Typical vegetation at Jornada includes grass and shrub areas. The principal 
grasses include black grama [Bouteloua eriopoda (Torr.) Torr.], mesa dropseed [Sporobolus flexuosus (Thurb. Ex Vasey) Rydb.], and three awn [Aristida purpurea Nutt. and Aristida pansa Wooton \& Standl.]. Shrubs and suffrutescents are commonly C3 plants and include honey mesquite [Prosopsis glandulosa Torr.], fourwing saltbush [Atriplex canescens (Pursh) Nutt.], broom snakeweed [Gutierrezia sarothrae (Pursh) Britton \& Rusby], and soaptree yucca [Yucca elata (Engelm.)].

Jornada ground sites were selected to represent grass, grass-shrub ecotone (transition), and shrub (mesquite) ecosystems. The transition site has vegetation components of both the grass and shrub sites. Dunes are developing at the transition site but are usually less than $1 \mathrm{~m}$ in height. Honey mesquite on coppice dunes dominates the shrub site. Bare soil with almost no vegetation dominates the areas between these coppice dunes. The sites will be referred to as Grass $\left(32.5981^{\circ} \mathrm{N}, 106.8471^{\circ} \mathrm{W}\right)$, Transition $\left(32.6068^{\circ} \mathrm{N}, 106.8695^{\circ} \mathrm{W}\right)$, and Mesquite $\left(32.6507^{\circ} \mathrm{N}, 106.8695^{\circ} \mathrm{W}\right)$ in this paper. As previously noted, rangeland at Jornada and throughout the US Southwest has degraded substantially, with significant gains in mesquite/coppice dune populations at the expense of beneficial grassland.

Since 1995, semi-annual remote sensing experiments using a range of aircraft and satellite detectors have been conducted at Jornada (JORNEX) to monitor land cover changes, assess landform distributions, and estimate water vapor and energy fluxes prior to and following seasonal monsoonal rainfall between June and September (Havstad et al. 2000). With the successful launch of NASA's EOS Terra satellite in December 1999, the experiments have been enhanced by dedicated observations with the ASTER sensor. 
Table 2

Selected ASTER/MODIS overpass dates.

\begin{tabular}{|c|c|c|c|c|c|c|}
\hline Count & Day & Month & Year & DOY & $\begin{array}{l}\text { Cumulative Days } \\
\text { (since } 1 / 1 / 2001 \text { ) }\end{array}$ & $\Delta$ Days \\
\hline 1 & 12 & Feb & 2001 & 43 & 42 & - \\
\hline 2 & 12 & May & 2001 & 132 & 131 & 89 \\
\hline 3 & 22 & Jul & 2001 & 203 & 202 & 71 \\
\hline 4 & 17 & Sep & 2001 & 260 & 259 & 57 \\
\hline 5 & 19 & Oct & 2001 & 292 & 291 & 32 \\
\hline 6 & 11 & Nov & 2001 & 315 & 314 & 23 \\
\hline 7 & 20 & Nov & 2001 & 324 & 323 & 9 \\
\hline 8 & 23 & Jan & 2002 & 23 & 387 & 64 \\
\hline 9 & 8 & Feb & 2002 & 39 & 403 & 16 \\
\hline 10 & 24 & Feb & 2002 & 55 & 419 & 16 \\
\hline 11 & 3 & Mar & 2002 & 62 & 426 & 7 \\
\hline 12 & 15 & May & 2002 & 135 & 499 & 73 \\
\hline 13 & 31 & May & 2002 & 151 & 515 & 16 \\
\hline 14 & 23 & Jun & 2002 & 174 & 538 & 23 \\
\hline 15 & 10 & Aug & 2002 & 222 & 586 & 48 \\
\hline 16 & 26 & Aug & 2002 & 238 & 602 & 16 \\
\hline 17 & 4 & Sep & 2002 & 247 & 611 & 9 \\
\hline 18 & 20 & Sep & 2002 & 263 & 627 & 16 \\
\hline 19 & 7 & Nov & 2002 & 311 & 675 & 48 \\
\hline 20 & 23 & Nov & 2002 & 327 & 691 & 16 \\
\hline 21 & 10 & Jan & 2003 & 10 & 739 & 48 \\
\hline 22 & 11 & Feb & 2003 & 42 & 771 & 32 \\
\hline 23 & 31 & Mar & 2003 & 90 & 819 & 48 \\
\hline 24 & 18 & May & 2003 & 138 & 867 & 48 \\
\hline 25 & 10 & Jun & 2003 & 161 & 890 & 23 \\
\hline 26 & 7 & Sep & 2003 & 250 & 979 & 89 \\
\hline 27 & 16 & Oct & 2003 & 289 & 1018 & 39 \\
\hline
\end{tabular}


From 47 scene acquisitions, 27 mostly cloud-free images acquired between February 2001 and October 2003 were selected for processing (Table 2). To ensure the best possible analyses, all visible/near-infrared (VNIR) images were georegistered to within $15 \mathrm{~m}$ accuracies and thermal infrared (TIR) images to within $90 \mathrm{~m}$ accuracies using common ground control points. Estimates of spectral emissivities were done by procedures previously described in section 2, with primary emphasis upon the NEM approach.

Since the objective of this study was to investigate the ability of emissivities to detect land cover change, analysis focused on shorter TIR wavelengths where most of the emissivity variability in soils occurs (Fig. 2). At wavelengths 10.5$12 \mu \mathrm{m}$, emissivity variability is small for most land cover conditions, whereas for $8-10 \mu \mathrm{m}$ interval variations potentially range from less than 0.8 to 0.98 . Not all soils exhibit this high spectral variability. Examples of low spectral variability include fine-grained, moist, and quartz-poor soils. In these circumstances, distinction between bare soils and soils covered with vegetation could be difficult. At Jornada soil emissivity variability is high, as exemplified by the dashed line in Fig. 2. Three ASTER bands sample the high-variability interval: 10,11 , and 12 . Band $11(8.475-8.825 \mu \mathrm{m})$ was used for this study because it is less sensitive to atmospheric correction uncertainties than Band 10 (8.125-8.475 $\mu \mathrm{m})$ and because it did not have the anomalous gain changes of Band 12 (8.925-9.275 $\mu \mathrm{m})$ discussed by Tonooka et al. (2003, 2005). Furthermore, Band 11 is nearly identical to MODIS band $29(8.4-8.7 \mu \mathrm{m})$, allowing spectral comparisons with this coarser resolution sensor.

To ensure the best possible TIR retrievals, ASTER thermal data were calibrated using both reference radiometric database coefficients and temporally based interpolation coefficients (needed to account for detector gain changes 
between routine updates). These interpolated values were particularly important for calibration of ASTER band 12.

To estimate vegetative cover, both remote sensing and ground measurements were used. For the remote sensing data, NDVI values were derived from ASTER bands 2 and $3 \mathrm{~N}$ reflectances previously aggregated to $90 \mathrm{~m}$. The reflectances were inferred from at-sensor radiances by using the $6 \mathrm{~S}$ atmospheric radiative transfer model (Vermote et al. 1997) and NOAA radiosonde profile data (http://raob.fsl.noaa.gov) from Santa Teresa, NM (EPZ, 31.90N, $106.70^{\circ} \mathrm{W}, \sim 75 \mathrm{~km}$ south of Jornada). For the ground measurements, the three sites previously mentioned (Grass, Transition, Mesquite) were used for semi-annual leaf area index (LAI) transect data. Each transect was $150 \mathrm{~m}$ long with LICOR LAI-2000 measurements collected at 1-meter intervals for three 30-m sections through vegetation including grass and shrubs. The measurements approximate total canopy cover, whether green or not.

To help verify ASTER emissivities at Jornada, ground collections of multiband TIR radiometric data from four sites were used (Table 3). In situ samples were acquired with a tripod-mounted 5 band CIMEL-312T instrument, while loosely-bagged soil samples were measured (hemispheric reflectance) in the laboratory using a Beckman spectrophotometer at the Jet Propulsion Laboratory, Pasadena, California (http://speclib.jpl.nasa.gov). Four of the resulting emissivity spectra were collected at the transect sites (1 at the Grass site, 1 at the Transition site, and 2 at the Mesquite site) and corresponded to quartz-bearing soils with low emissivities between 8 and $12 \mu \mathrm{m}$. The fifth spectrum corresponded to gypsum from the western edge of White Sands $\left(32.8222^{\circ} \mathrm{N}, 106.4125^{\circ} \mathrm{W}\right)$. In contrast to quartz-rich soils, gypsum has generally high emissivities (>0.96) except for 8.5-8.9 $\mu \mathrm{m}$ wavelengths, where it 
Table 3

Field, laboratory, and ASTER band 11 emissivities at the Grass, Transition, Mesquite, and White Sands sites. Two soil sample types were acquired at Mesquite. Data sources were in situ Cimel-312T radiometric observations and bagged surface samples for laboratory spectrophotometry.

\begin{tabular}{ccc}
\hline Site & Source & B11 Emissivity \\
\hline Grass & Cimel & 0.893 \\
& Lab & 0.882 \\
& ASTER & 0.886 \\
Transition & Cimel & 0.800 \\
& Lab & 0.803 \\
Mesquite & ASTER & 0.872 \\
(Bright Sand) & Lab & 0.718 \\
& ASTER & 0.703 \\
Mesquite & Cimel & 0.847 \\
(Dark Sand) & Lab & 0.880 \\
& ASTER & 0.853 \\
White Sands & Cimel & 0.740 \\
(Gypsum) & Lab & 0.724 \\
& ASTER & 0.725 \\
\hline
\end{tabular}

is strongly reflective $(\epsilon \sim 0.72-0.74)$. Agreement between field, laboratory, and ASTER data are generally very good. Emissivity differences were less than 0.016 in most instances. Exceptions occurred where samples could not be collected intact (surface crusts at Mesquite) and where ASTER could not resolve spatial heterogeneities (at Transition). 


\section{Emissivity Retrieval Uncertainty}

Although accurate retrieval of land surface emissivities is important, a greater concern for land cover change assessment is consistent emissivity retrieval, since it is the temporal change of emissivity that will determine the effectiveness of the analysis. When considering interfering factors for change assessment, four are critical: instrumental noise, georegistration errors, anomalously wet soils, and inaccurate atmospheric corrections. Fortunately, most of these errors for the Jornada study were small and unimportant. In particular, instrumental errors in the TIR bands were $<0.4{ }^{\circ} \mathrm{C}$ (Tonooka et al. 2005). Georegistration errors were also small, $<90 \mathrm{~m}$, because all scenes were registered with ground control points. Considering the variability scale of vegetation at Jornada ranges between 3 and 8 m Pelgrum (2000), in conjunction with a 90 m pixel size, apparent temporal changes in emissivities due to misregistrations were not significant. Wet soils too were rarely a problem because rainfall shortly before selected overpasses did not occur. The one exception occurred in September 2002, when rainfall was heavy shortly before overpass time. The effect of this event is discussed further in Section 5.

Since three of four critical interfering factors were not significant concerns for the Jornada study, the greatest concern for change analyses was ensuring adequate removal of atmospheric effects. Inaccurate corrections could overwhelm small emissivity changes and invalidate results. Thus, quantifying the potential effects of atmospheric correction uncertainty became important, especially when using atmospheric profiles that were not acquired at overpass times, nor co-located over Jornada. 
To assess correction uncertainties, a sensitivity analysis of atmospheric profile correction was conducted using simulations. By assuming temporal variability equivalence between the profile over the radiosonde site and profiles above Jornada, and by developing relationships between the correction terms and columnar water vapor (the dominant factor affecting TIR corrections), the expected effect of uncertain TIR corrections upon emissivity could be estimated.

The tests were performed in four steps. The first step quantified variability of columnar water vapor over the Santa Teresa radiosonde site (EPZ) by considering the atmospheric database from 2001 to 2003. The second step established empirical relationships between columnar water vapor and atmospheric correction terms for each of the five ASTER TIR bands. This was done by performing simulations using MODTRAN radiative transfer code and a subset of the EPZ database. The third step generated apparent emissivities using the relationships from step 2 and the variability data obtained from step 1. Specifically, MODTRAN simulations were performed and applied to the NEM algorithm for each of the 27 ASTER scenes using radiosonde profiles and normally distributed perturbations to the correction terms. The fourth step extracted the statistical outcomes for ASTER band 11 emissivities from each site of interest.

In step one, columnar water vapor for $2159 \mathrm{EPZ}$ radiosonde profiles was computed and plotted by time (Fig. 3). Water vapor amounts ranged $\sim 0.2-3.4$ $\mathrm{cm}$ with strong seasonal increases associated with summer monsoons. Day-today water vapor also varied seasonally, ranging $\sim 25-45 \%$ of columnar water amounts. To include a wide range of realistic simulated atmospheric conditions throughout the year, the upper limit value (45\%) was used for subsequent simulations. 
Table 4

Coefficients to estimate ASTER TIR atmospheric correction parameters based on columnar water vapor.

\begin{tabular}{cccccccccc}
\hline Band & & $\tau$ & & \multicolumn{3}{c}{$\mathrm{L} \uparrow$} & & \multicolumn{3}{c}{$\mathrm{L} \downarrow$} \\
$i$ & $\mathrm{~b}_{0}$ & $\mathrm{~b}_{1}$ & $\mathrm{p}$ & $\mathrm{b}_{0}$ & $\mathrm{~b}_{1}$ & $\mathrm{p}$ & $\mathrm{b}_{0}$ & $\mathrm{~b}_{1}$ & $\mathrm{p}$ \\
\hline 10 & -0.08447 & -0.1859 & 0.7935 & 273.4 & 1117.4 & 0.7420 & 355.2 & 1992.2 & 0.7218 \\
11 & -0.07470 & -0.1180 & 0.8247 & 258.4 & 788.8 & 0.7943 & 428.7 & 1325.6 & 0.8116 \\
12 & -0.06872 & -0.0722 & 0.9783 & 244.6 & 557.2 & 0.9144 & 433.6 & 908.9 & 0.9439 \\
13 & -0.03421 & -0.0590 & 1.3600 & 172.9 & 466.5 & 1.2782 & 294.2 & 780.4 & 1.2551 \\
14 & -0.02422 & -0.0780 & 1.3178 & 100.9 & 575.2 & 1.2378 & 172.4 & 946.9 & 1.2192 \\
\hline
\end{tabular}

In step two, MODTRAN runs were performed using a subset (359) of the 2001-2003 atmospheric profile database. Outputs were filtered with ASTER TIR spectral response functions, modeled with power functions, and checked against the remainder of the database. The estimation functions were:

$$
\tau_{i}=\mathrm{b}_{0 i}+\exp \left[\mathrm{b}_{1 i} \mathrm{w}^{\mathrm{p}_{i}}\right]
$$

for atmospheric transmissivity, and:

$$
\mathrm{L}_{i}=\mathrm{b}_{0 i}+\mathrm{b}_{1 i} \mathrm{w}^{\mathrm{p}_{i}}
$$

for path radiance (upwelling and downwelling). The terms $\mathrm{b}_{0, i}, \mathrm{~b}_{1, i}$, and $\mathrm{p}_{i}$ correspond to the parameters in Tab. $4 . \mathrm{w}$ is columnar water vapor $(\mathrm{cm})$. Eqs. 6 and 7 are valid for columnar water vapor amounts between $0.25 \mathrm{~cm}$ and 2.5 $\mathrm{cm}$.

Graphical examples of these functions compared with MODTRAN output values are shown in Fig. 4 for ASTER band 11.

In step three, 1001 MODTRAN simulations were run using randomly gener- 
ated, Gaussian distributed, $\tau$ (transmissivity), L $\uparrow$ (upwelling path radiance), and $\mathrm{L} \downarrow$ (hemispherically integrated downwelling path radiance) correction terms for each of the 27 ASTER scenes. The chosen number of simulations was based on a compromise between the need for large sample sizes and time needed for computations. Distribution plots from test runs indicated 101 simulations were insufficient, whereas output from 10001 runs were only marginally different from 1001 runs (odd numbers were used to simplify median sampling). Atmospheric corrections were done according to the atmospheric radiative transfer equation:

$$
\mathrm{L}_{\text {surface }, \mathrm{i}}=\frac{\mathrm{L}_{\text {sensor }, \mathrm{i}}-\mathrm{L} \uparrow_{\mathrm{i}}}{\tau_{\mathrm{i}}}-\left(1-\epsilon_{\mathrm{i}}\right) \mathrm{L} \downarrow_{\mathrm{i}}
$$

where $\mathrm{L}_{\text {surface, } \mathrm{i}}$ is radiance emitted by the surface for channel $i$ and $\mathrm{L}_{\text {sensor, } \mathrm{i}}$ is radiance observed by the sensor. For each scene, the closest-in-time radiosonde profile was used to derive the mean value of each of the atmospheric correction terms in Eq. 8. Apparent instead of observed columnar water vapor values for each term were then computed using the inverse of Eqs. 6 and 7. This approach accounts for differences between predicted and observed atmospheric transmissivities and path radiances. Using the columnar water variability estimated in step 1 as the standard error of mean water vapor, random values of apparent water vapor were generated to allow forward solutions of Eqs. 6 . Having obtained simulated the atmospheric correction terms $\tau, L_{\uparrow}$, and $L_{\downarrow}$, surface emissivities could be estimated from the NEM algorithm.

Lastly, in step four ASTER band 11 estimates for each pixel (1.05E9 of these) were consolidated for statistical analysis. Aggregation by target site resulted in data such as shown in Fig. 5, where ASTER band 11 emissivity quantiles are plotted for two sites spanning 2001-2003. Fig. 5 illustrates outcomes for two 
sites denoted as 'Degraded' and 'Reference'. These sites did not have ground observations and were selected for comparative purposes. The 'Degraded' site is the location of apparent land cover degradation and will be further discussed below. The 'Reference' site was chosen because it had no significant land cover change, as seen from remote sensing data. The site coincides with a fenced pasture having restricted access. In Fig 5a, the temporal progression of ASTER band 11 emissivities are displayed for the 'Degraded' site. Fig. 5b displays the temporal progression for the nearby 'Reference' site, where emissivities showed less change. The symbols are conventional box and whisker displays of quantiles (1st quartile, median, 3rd quartile), except for the whiskers, which represent the full emissivity range. All 27 selected overpass times could be used for the 'Reference' site, but two fewer were used for the 'Degraded' site due to limited ASTER coverage for overpasses on 8 February and 7 November 2002. To estimate emissivity uncertainties caused by random errors in atmospheric corrections, linear trend lines were fit to data in each site. De-trending data for the 'Reference' site was statistically insignificant $\left(\mathrm{R}^{2}=0.008, \mathrm{p}<2.2 \mathrm{E}-16\right)$. Residual error for the 'Degraded' site was 0.014, and for the 'Reference' site was 0.016 , meaning that random atmospheric perturbations to NEM-derived Band 11 emissivities were $\leq 1.6 \%$.

\section{Observed Temporal Changes}

Temporal change in land cover between 2001 and 2003 over Jornada was assessed in two ways: one in terms of change in land surface emissivities, and another in terms of change in NDVI. Although seasonal variations were likely

embedded within the data series, only 3-year linear trends were considered be- 
cause this was the simplest and least error-prone analysis possible. Modeling variations at higher orders would have placed greater demands on accurate temporal sampling and would not allow suppression of erroneous short term (weekly to monthly) changes.

\subsection{ASTER Band 11 Emissivity Change}

Considering the georegistered stack of 27 ASTER images, linear fits were computed for each pixel location by regressing band 11 emissivities against cumulative days since 1 January 2001. The resulting emissivity slope values (Fig. 6) ranged between $-3 \%$ year $^{-1}$ to $+1 \%$ year $^{-1}$. For most of the Jornada region band 11 emissivity trends were small $(<1 \%)$, suggesting no significant linear change in emissivity patterns occurred for this three year period. However, Fig. 6 also revealed spatially coherent regions - one of them $\sim 5 \mathrm{~km} \mathrm{x} 10 \mathrm{~km}-$ near the southern and western boundaries of the USDA Jornada Range, where emissivities decreased by $2-3 \%$ year $^{-1}$. These decreases were greater than the 1.6\% residual uncertainty estimated from the atmospheric simulation tests. A portion of this emissivity decrease region is delimited by the large black circle (repeated in Figs. 7 and 10). By comparison, a trapezoidal-shaped area (surrounding the small black circle indicating the 'Reference' site) showed negligible emissivity change. The explained variations of these emissivity changes are indicated in Fig. 7, which shows that the estimated linear trends have $\mathrm{R}^{2}$ values up to 0.85 within the larger circled area. The trends were highly significant, with $\mathrm{p}$ values $<2 \mathrm{E} 10^{-16}$. The extents of both the trend and the $\mathrm{R}^{2}$ values, furthermore, were strongly correlated to land use patterns. Note for example the abrupt spatial termination of decreased emissivities along a roadway to 
Table 5

Emissivity trend estimation over the 'Degraded' site with NEM, TES, and TISI.

\begin{tabular}{cccc}
\hline Method & Slope (\%/year) & Standard Error (\%/year) & $\mathrm{R}^{2}$ \\
\hline NEM & -2.09 & 0.036 & 0.63 \\
TES & -2.70 & 0.043 & 0.66 \\
TISI & -2.09 & 0.039 & 0.60 \\
\hline
\end{tabular}

the west and along rangeland boundaries to the north. These terminations could not have been caused by instrumental, processing, or atmospheric correction errors, meaning that the observed decreased emissivities were not data artifacts but were indicative of physical land cover changes corresponding to rangeland management practices.

These emissivity changes are consistent with retrieval algorithms other than NEM. To show this, the previously discussed 'Degraded' and 'Reference' sites were selected. Comparison of trends (Fig. 8) obtained from three different emissivity retrieval algorithms - NEM, TES, and TISI - showed similar linear trends for both sites. Shown in black are emissivities for the 'Degraded' site, and shown in gray are emissivities for the 'Reference' site. Absolute emissivity values from NEM, TES, and TISI significantly differed, despite use of identical remote sensing data and initial emissivities. However, the trend line slopes were similar, -2.09 to $-2.70 \%$ year $^{-1}$, with $R^{2}$ values ranging 0.60 to 0.66 (Table 5). Slopes for the NEM and TISI emissivity trends were statistically identical and only slightly different from the TES trend. Standard errors for methods were also similar $\left(\sim 0.04 \% /\right.$ year $\left.^{-1}\right)$.

The significance of the coherent regions can also be tested by comparison against regions with no land cover change. One such region is White Sands, a $\sim 20 \mathrm{~km}$ x $25 \mathrm{~km}$ area covered by generally dry, unvegetated gypsum sand. 
Gypsum is an especially good stability test for ASTER band 11 due to its large potential sensitivity, ranging between 0.72 for a dry surface and 0.98 for a wet surface. Selecting a 12 x 20 pixel patch well within the White Sands area (1080 m x $1800 \mathrm{~m}, 32.8348 \mathrm{~N}, 106.2925 \mathrm{~W})^{3}$ showed no significant emissivity change occurred over the 2001-2003 period (Fig. 9). Linear trend analysis for 9 scenes returned a slope of $0.3 \% /$ year $^{-1}$, with $\mathrm{R}^{2}=0.02$ and $\mathrm{p}$ value of $9.5 \mathrm{E}^{-15}$.

\subsection{MODIS Band 29 Emissivity Change}

The spatially coherent decreasing emissivity zones identified by ASTER are sufficiently large to compare with 1-km Terra MODIS observations. If sensors such as MODIS corroborate ASTER-based results, there will be not only the possibility of greatly expanded regional studies at $1 \mathrm{~km}$ resolution but also much more confidence that the changes are real and not instrumentation artifacts. MODIS has only three TIR bands comparable to ASTER's five (Fig. 2) but can still be analyzed with the NEM, TES or TISI approaches. For compatibility, the NEM approach was used for MODIS. The spectral band equivalent to ASTER band 11 is MODIS band 29, with the MODIS response weighted for slightly shorter wavelengths relative to ASTER band 11 .

MODIS band 29 emissivity changes were estimated using the same 27 overpass days identified in Table 2. The resulting patterns (Fig. 10) are remarkable for their similarity to changes observed by ASTER (Fig. 6). Despite the coarser spatial resolution, band 29 emissivities from MODIS show the same $3 \%$ year $^{-1}$ decrease within the 'Degraded' site (larger circle). Just as for the

$\overline{3}$ ASTER resolution did not allow selecting the same site (Tab. 3) as used previously for ground samples because of mixed-pixel problems. 
ASTER-based estimation, the MODIS emissivity trend within the 'Reference' site (smaller circle) showed no significant change over the 2001-2003 period. Five km eastward of the main region with decreasing emissivities lies a smaller region (with light gray tones) where emissivities increased by $1 \%$. The same patch of increasing emissivity was observed by ASTER (Fig. 6).

\subsection{ASTER NDVI Change}

Viewing Jornada from an NDVI perspective showed similar but less significant temporal changes than seen with emissivity (Fig. 11). Shown are trends for five sites: the 'Degraded' site, the 'Reference' site, and the three transect sites: Grass, Transition, and Mesquite. Plotted are NDVI quantiles for each site by elapsed days since 1 January 2001. The trendlines are least squares fits to the NDVI data over each site. The gray boxes approximate the extent of the monsoonal season, the most likely period for rainfall.

Visual inspection of trends suggested that NDVI decreased over time in the same way as it did for emissivity, including a weak suggestion of seasonally periodic changes. However, NDVI values at Jornada were usually low- ranging between 0.0 and 0.2 - and there was no apparent distinction in vegetation changes between the 'Degraded' and 'Reference' sites. Statistical analyses confirmed this observation. Unlike emissivity trends (Tab. 5), the NDVI linear trends were not significant (Tab. 6), with p values $<2.2 \mathrm{E}-16$. Considering standard errors, NDVI slopes for all five sites were indistinguishable. $\mathrm{R}^{2}$ values were all negligible, meaning that NDVI changes over the three years could not be explained by linear trends. 
Table 6

NDVI change statistics for five Jornada sites. Slope and standard error of slope shown as NDVI $\%$ year $^{-1}$.

\begin{tabular}{ccccc}
\hline Site & Slope & Standard Error & Residual (\%) & $\mathrm{R}^{2}$ \\
\hline Degraded & 2.3 & 0.2 & 6.1 & 0.06 \\
Reference & 2.3 & 0.2 & 5.8 & 0.07 \\
Grass & 2.5 & 0.2 & 6.0 & 0.08 \\
Transition & 2.3 & 0.2 & 6.0 & 0.07 \\
Mesquite & 2.6 & 0.2 & 6.1 & 0.08 \\
\hline
\end{tabular}

To the extent that NDVI observations were correlative to vegetation cover, these results can be qualitatively checked by comparison against LAI transects collected at the Grass, Transition, and Mesquite sites. The transects were important independent observations of vegetation cover, but unfortunately because of their locations and sampling frequencies, they could not be used in a rigorous way to confirm vegetation conditions in the 'Degraded' region. Fig. 12 summarizes the ground observations for 2001-2003. The three monthly rainfall bars bars at the base of the plot show that cumulative rainfall did not correspond to monsoon periods.

Generally, LAI values suggest a three-year decrease from 1.36 to $0.54-0.76$ for the Grass and Transition sites. LAI values at the Mesquite site vary widely between 1.89 to 0.37 , making trend assessment difficult. Site trends inferred by line segments are suggestive of decreasing LAI values at the Grass and Transition sites from May 2001 (Cumulative day 131) until October 2002 (Cumulative day 640). Causes for the anomalously low LAI data in September 2001 (Cumulative day 259) are unknown. These data were collected after unusually heavy rainfall and ponded water. With one exception for the Mesquite site, LAI values remained low $(<0.68)$ from October 2002 until October 2003. 
Table 7

LAI regression statistics for Jornada sites with respect to ASTER band 11 emissivities (left) and ASTER NDVI (right).

\begin{tabular}{ccccccc}
\hline Site & \multicolumn{3}{c}{ LAI vs. Emissivity } & \multicolumn{3}{c}{ LAI vs. NDVI } \\
& Slope & $\mathrm{R}^{2}$ & Standard Error & Slope & $\mathrm{R}^{2}$ & Standard Error \\
\hline Grass & 21.38 & 0.99 & 1.01 & 11.01 & 0.52 & 4.73 \\
Transition & 22.41 & 0.81 & 5.22 & 13.70 & 0.81 & 3.19 \\
Mesquite & 58.02 & 0.86 & 11.53 & 14.46 & 0.50 & 6.46 \\
\hline
\end{tabular}

Explanation for the relatively poor discrimination ability of NDVI data may be provided by comparison against LAI transect data (Fig. 13). Plotted in the top figure are LAI vs. ASTER band 11 emissivities, and plotted in the bottom figure are LAI vs. NDVI. For conditions ranging between bare soil and full cover, an linear-exponential relationship between LAI, emissivity, and NDVI could be expected, where asymptotes were reached for LAI values greater than 3.0. For Jornada land cover conditions linear fits (indicated as solid lines) were sufficient because LAI values were less than 2.0. Six LAI transect observations were made, but one set made on 17 September 2001 was excluded (open symbols) because of very wet surface conditions. Such conditions affected all sites by increasing emissivities.

The relationship between LAI and NDVI agrees with the previous time series (Fig. 11) that showed trends with little distinction between sites. Statistical results (Table 7) show moderate to good explained variance (0.50-0.81). LAI/NDVI slope relationships were similar and agreed within standard errors.

The relationship between LAI and emissivity, on the other hand, suggests a stronger correlation exists for the sparse canopies at Jornada. Explained variance was good to excellent (0.81-0.99) for the three sites with significant dis- 
crimination between vegetation-emissivity slope relationships at the Mesquite site and the Transition and Grass sites (58.02 LAI/emissivity vs. 22.41 and 21.38). This discrimination is possibly related to spatial clumping of vegetation. At the Mesquite site, shrubs are strongly clumped with large bare soil expanses between dunes but at the Transition and Grass sites the vegetation is more uniformly distributed. A consequence of this clumping is that increases of LAI at the Mesquite site obscure significantly less soil than do increases at the other two sites. NDVI appears insensitive to clumping because the bulk of the canopies are non-green.

\section{Emissivity-NDVI relationship}

An issue not discussed so far is the relationship between emissivity and vegetation indices such as NDVI over arid landscapes. Some suggest a meaningful relationship between them exists (e.g., Van de Griend and Owe 1993, Valor and Caselles 1996, Bolle et al. 2006), meaning that difficult-to-obtain emissivity data could be replaced with much more available NDVI data. This substitution would be especially valuable because VNIR data also typically have greater spatial resolutions than possible with TIR data. The basis for the relationship is that surface emissivities are low over bare soils and high over vegetation canopies. Soil, when dry, often exhibits low emissivities (0.9 or less), while vegetation canopies are efficient scatterers and effectively blackbodies. Hence, as long as vegetation canopies are also photosynthetically active, vegetation indices should be able to track emissivity changes indirectly. Van de Griend and Owe (1993), for example, proposed a logarithmic formula relating broadband emissivity to ground-based NDVI observations based on 
calibrations over sites in Botswana:

$$
\epsilon=1.0094+0.047 \ln (\mathrm{NDVI})
$$

Van de Griend and Owe (1993) suggest scale independence for the $\epsilon$-NDVI relationship and demonstrate its use at satellite remote sensing scales. For longer wavelengths in the TIR window, 10.5-12.5 $\mu \mathrm{m}$, Valor and Caselles (1996) show that by considering vegetation structure, modification of Eq. 9 allows its applicability to regions outside of Botswana. The question remains, however, how well models such as Eq. 9 could predict emissivities for land covered by sparse, dormant vegetation.

Using ASTER TIR and VNIR data from 15 different overpasses during 20012003 at Jornada (Fig. 14), the question can be partly answered. For this semiarid landscape, dependence of ASTER Band $11(8.475-8.825 \mu \mathrm{m})$ emissivity upon NDVI is in most instances questionable. With possible exceptions for scenes acquired after 15 May 2002, Band 11 emissivities are poorly correlated to NDVI, and there is a non-unique relationship for NDVI values between 0.1 and 0.2 . For NDVI values less than 0.2 , the slope of the scatter plots is essentially vertical, meaning there is no meaningful relationship between NDVI and spectral emissivities. For most dates displayed in Fig. 14, the maximum emissivity was nearly reached by NDVI $\sim 0.2$. The black curve (Eq. 9 ), even if translated vertically, did not accurately represent observations, with emissivity discrepancies sometimes exceeding $3 \%$.

Performing these analyses for broadband emissivities, instead of narrow band ones, likely would not substantively change these results (Gieske et al. 2004). Using a wider spectral interval would reduce the large emissivity variability 
seen at low NDVI while maintaining the flat response for higher NDVI. This lower variability may explain some of the success reported by Momeni and Saradjian (2007), who evaluated emissivities at 10.5-11.5 $\mu \mathrm{m}$ wavelengths at $1 \mathrm{~km}$ spatial resolution. In contrast, Jornada results show no reliable relationship between emissivity and NDVI exists at 90-m scales. While there could be ways to infer emissivities, using NDVI improved with geometrical parameters (Jiménez-Muñoz et al. 2006), the likelihood of its success in Jornada-like environments is poor because emissivity variability is not well-correlated to plant greenness.

\section{Discussion}

Retrieval and analysis of ASTER TIR data over southern New Mexico rangeland shows strong, consistent, and coherent regions of decreasing band 11 emissivities over the three-year period, indicating that land cover change for this environment can be monitored from space. ASTER thermal infrared observations over the Jornada Experimental Range and the adjacent New Mexico State University Ranch have revealed patches of land, $\sim 5 \mathrm{~km}$ x $10 \mathrm{~km}$, where emissivities at $8.6 \mu \mathrm{m}$ decreased on the order of $3 \%$ year $^{-1}$, with early 2001 NEM-based emissivities of $\sim 0.93$ decreasing to $\sim 0.87$ by late 2003 .

We interpret these patches as areas of decreased vegetation densities where sparsely vegetated land were further degraded, exposing greater amounts of bare soil over a three year period. What is notable for the emissivity data is not the short term, seasonal changes in vegetation - these might be observed

in a better way using VI data - but rather the inter-annual changes regardless of seasonality. The physical reason for this difference is explained by the 
dynamics of rangeland vegetation and the fact that VI and emissivity observations respond to different biochemical and structural properties of vegetation. VI responds to plant chlorophyll densities, while emissivity responds to plant canopy geometry and patterns between plant canopies. This difference in response was described in Section 6. Since VI changes are seasonal according to plant growth cycles, their variability within a year is just as large as between years, which means that it can be difficult to distinguish long-term change from short-term changes. This difficulty has been noted by others (e.g., Li et al. 2005).

Emissivity changes, on the other hand, are less likely to show such seasonal variability over persistent vegetation because the multi-scattering effects result from plant matter regardless of chlorophyll content. At time scales greater than a year, plant distributional patterns do change, and in these cases corresponding emissivities changes can be detected. Hence, emissivity variability within a year (absent surface wetting events) is small, while variability between years could be large. To illustrate how the land cover change could be estimated, the regression results from comparing LAI transect data to band 11 emissivities (Tab. 7) were applied to the entire collection of 27 ASTER scenes and plotted as dashed gray lines in Fig 12. The tentative trends (i.e., regression results were based on too few observations to warrant greater certainty) show how LAI values at the Mesquite site may have decreased from $\sim 2.0$ to 1.3 between 2001 and 2003. For the Transition and Grass sites, the decrease appears to be from 1.5 to 0.8 .

Alternative interpretations of the Jornada emissivity patterns were also considered, such as the possibility of data collection and processing artifacts. These included TIR calibration errors, detector degradation, and inaccurate atmo- 
spheric corrections, none of which could be reconciled with all observations. TIR calibration and detector problems were unlikely because the ASTER gains were episodically monitored and updated to reflect correct gains and offsets. Poor atmospheric corrections, though certainly a concern, were demonstrated to potentially cause emissivity errors no greater than $1.6 \%$. Furthermore, the correction errors from radiosonde profiles would not cause systematic trends, nor would such errors induce the discrete and the well-delineated patches evident in Fig. 6.

Another interpretation is that the emissivity changes were due to changes in soil emissivity. These could be induced by various factors such as change in surface organic matter, surface texture, and surface moisture. Soil emissivities in particular have some dependency upon surface grain size (e.g., Salisbury and Eastes 1985). It is plausible - though in this instance unverifiable - that the observed emissivity changes were related to grazing activity which may have disturbed the surface soil texture. Soil emissivity changes can also be seen with changing surface moisture, but in these cases the changes occur over short time spans, such as observed for the September 17, 2002 overpass.

Considering that these alternatives were either unlikely or conjectural, the more probable explanation for the three-year emissivity patterns, whether decreasing or increasing, is due to change in vegetation canopy densities. For sparsely vegetated terrain, the interaction between high-emissivity vegetation and low-emissivity soils explains in a physically meaningful way the spatial and temporal distribution of observed emissivity patches. As vegetation densities increase, low emissivity surfaces are increasingly masked by higher emissivity surfaces. There is also evidence from ground transect data that the temporal emissivity decrease is associated with LAI decreases at three peripheral sites 
(Fig. 12 and Table 7). With two exceptions, canopy LAI values at the Grass, Transition, and Mesquite sites dropped from $\sim 1.4$ to $\sim 0.6$, a change of more than $50 \%$. The environmental causes for the vegetation density changes are unknown and apparently are not linked to short term precipitation patterns (Fig. 12).

\section{Conclusions}

Detection of land cover change is an important role for remote sensing whereby long-term observations can be used to monitor spatial and temporal seasonal to multi-year patterns in vegetation cover. The usual approach to this task is to construct VI maps, derived from normalized red and near infrared data. Generally these maps have good quality and are extremely valuable for tracking seasonal vegetation changes. Nevertheless, VI techniques distinguish nongreen vegetation from background soils with difficulty, which means that signals from long term changes can be overwhelmed by seasonal effects. Such circumstances commonly arise for both cultivated and uncultivated lands.

In this study we have shown a complementary approach that may improve abilities to discriminate vegetation cover regardless of plant color. Using thermal infrared observations from a one-of-a-kind remote sensing instrument, ASTER, seasonal land cover changes can be detected by using spectral emissivities. Unlike VI data, TIR emissivity data respond to changes in vegetation canopy densities and to changes in surface soil properties. Provided that the emissivity for soil is significantly different from vegetation, emissivity changes over time can be detected. When viewed at multi-year time scales, long-term changes in land cover, not otherwise recognized, can be mapped spatially at 
100-m scales.

Analysis of 27 ASTER scenes over the Jornada Experimental Range between 2001-2003 revealed spatially coherent land cover patterns with decreasing band 11 emissivities. At these locales, emissivities declined at the rate of $\sim 3 \%$ year $^{-1}$ with high confidence $\left(\mathrm{R}^{2}\right.$ values up to 0.82$)$. The identification of these regions, corroborated by $1 \mathrm{~km}$ MODIS TIR data, supports ground-based LAI observations where cover decreased from over 1.0 to $\sim 0.7$. Comparable NDVI observations showed similar decreases at all sites, but the linear trends were indistinguishable and statistically insignificant.

These results highlight the importance of multispectral thermal infrared data that includes observations at wavelengths within $8-9.5 \mu \mathrm{m}$. The value of TIR data extends beyond land surface temperature retrieval to include the information rich portion of the TIR window. Commonly, TIR detectors sample TIR data at wavelengths between $10-13.5 \mu \mathrm{m}$ for split window analyses. For land surface applications, variability of surface emissivities at these wavelengths is typically small and difficult to use for change assessment in the manner described in this study. A TIR remote sensing strategy that is better for both temperature and emissivity estimation is to include observations within the 8-9.5 $\mu \mathrm{m}$ interval, where emissivity variations due to soils and vegetation are frequently large. These data, in combination with longer wavelength TIR data, will provide valuable land cover information unavailable using other remote sensing bands. Future work will expand the emissivity change assessment to more sites throughout the U.S. Southwest. 


\section{Acknowledgments}

This work was supported in part by NASA EOS Grant 03-OES-02 and by the USDA/ARS Jornada Experimental Station. The laboratory soil sample measurements were made by Cindy Grove, Jet Propulsion Laboratory, California Institute of Technology, Pasadena, California. Data analysis and presentation were greatly facilitated by using the $\mathrm{R}$ package ( $\mathrm{R}$ Development Core Team 2006). Precipitation data were provided by the Jornada Long-Term Ecological Research (LTER) project and were funded by the U.S. National Science Foundation (Grant DEB-92-40261). 


\section{References}

Anyamba, A. and Eastman, J.: 1996, Interannual variability of NDVI over Africa and its relation to El Niño/Southern Oscillation, Int. J. Remote Sens. 17(13), 2533-2548.

Bannari, A., Pacheco, A., Staenz, K., McNairn, H. and Omari, K.: 2006, Estimating and mapping crop residues cover on agricultural lands using hyperspectral and IKONOS data, Remote Sens. Environ. 104(4), 447-459.

Baret, F., Clevers, J. and Steven, M.: 1995, The robustness of canopy gap fraction estimates from red and near-infrared reflectances: a comparison of approaches, Remote Sens. Environ. 54, 141-151.

Becker, F. and Li, Z.-L.: 1990, Temperature-Independent Spectral Indices in thermal infrared bands, Remote Sens. Environ. 32, 17-33.

Bolle, H.-J., Eckardt, M., Koslowsky, D., Maselli, F., Miralles, J. M., Menenti, M., Olesen, F.-S., Pekov, L., Rasool, I. and de Griend, A. V. (eds): 2006, Meditteranean Land-Surface Processes Assessed from Space, Springer, chapter 5, pp. $257-265$.

Buffington, L. and Herbel, C.: 1965, Vegetational changes on a semidesert grassland range from 1853 to 1963, Ecol. Monographs 35, 139-164.

Byrne, P., Crapper, P. and Mayo, K.: 1980, Monitoring land-cover change by principal component analysis of multitemporal Landsat data, Remote Sens. Environ. 10, 175-184.

Carlson, T. and Ripley, D.: 1997, On the relation between NDVI, fractional vegetation cover, and leaf area index, Remote Sens. Environ. 62, 241-252.

Chehbouni, A., Goodrich, D., Moran, M., Watts, C., Kerr, Y., Dedieu, G., Kepner, W., Shuttleworth, W. and Sorooshian, S.: 2000, A preliminary synthesis of major scientific results during the SALSA program, Agric. For. 
Meteorol. 105, 311-323.

Choudhury, B. J.: 1987, Relationships between vegetation indices, radiation absorption, and net photosynthesis evaluated by a sensitivity analysis, $R e$ mote Sens. Environ. 22, 209-233.

Dash, P., Göttsche, F.-M., Olesen, F.-S. and Fischer, H.: 2002, Land surface temperature and emissivity estimation from passive sensor data: Theory and practice-current trends, Int. J. Remote Sens. 23(13), 2563-2594.

Dash, P., Göttsche, F.-M., Olesen, F.-S. and Fischer, H.: 2005, Separating surface emissivity and temperature using two-channel spectral indices and emissivity composites and comparison with a vegetation fraction method, Remote Sens. Environ. 96, 1-17.

Daughtry, C., E.R. Hunt, J., Doraiswamy, P. and McMurtrey, J.: 2005, Remote sensing the spatial distribution of crop residues, Agron. J. 97(3), 864-871.

Dial, G., Bowen, H., Gerlach, F., Grodecki, J. and Oleszczuk, R.: 2003, IKONOS satellite, imagery, and products, Remote Sens. Environ. 88(12), 23-36.

Diouf, A. and Lambin, E.: 2001, Monitoring land-cover changes in semi-arid regions: remote sensing data and field observations in the Ferlo, Senegal, $J$. Arid Environ. 48(2), 129-148.

Elvidge, C. D.: 1988, Thermal infrared reflectance of dry plant materials:

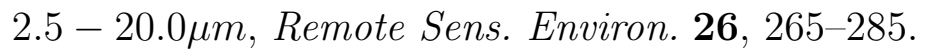

Falkenmark, M.: 1997, Meeting water requirements of an expanding world population, Philosoph. Trans. Royal Soc. B: Biological Sciences 352(1356), 929936.

Fang, H.: 1998, Rice crop area estimation of an administrative division in China using remote sensing data, Int. J. Remote Sens. 19(17), 3411-3419.

French, A., Schmugge, T. and Kustas, W.: 2000, Discrimination of senes- 
cent vegetation using thermal emissivity contrast, Remote Sens. Environ. $74,249-254$.

Fuchs, M. and Tanner, C.: 1966, Infrared thermometry of vegetation, Agron. J. 58, 597-601.

Fuchs, M. and Tanner, C.: 1968, Surface temperature measurements of bare soils, J. Appl. Met. 7, 303-305.

Gibbens, R., McNeely, R., Havstad, K., Beck, R. and Nolen, B.: 2006, Vegetation changes in the Jornada Basin from 1858 to 1998, J. Arid Environ. 61.

Gieske, A. S., Wubett, M. T., Timmermans, W. J., Parodi, G. N., Wolski, P. and Arneth, A.: 2004, Temperature-emissivity separation with ASTER and LANDSAT 7 imagery validation on the fring of the Okavango Delta, Botswana, in M. Owe, G. D’Urso, J. F. Moreno and A. Calera (eds), Remote Sensing for Agriculture, Ecosystems, and Hydrology V, Proceedings of the SPIE, Vol. 5232, pp. 489-498.

Gillespie, A.: 1985, Lithologic mapping of silicate rocks using TIMS, The TIMS data users' workshop, Technical report, Jet Propulsion Laboratory. JPL Publication 86-38, pp. 29-44.

Gillespie, A., Rokugawa, S., Matsunaga, T., Cothern, J., Hook, S. and Kahle, A.: 1998, A temperature and emissivity separation algorithm for advanced spaceborne thermal emission and reflection radiometer (ASTER) images, IEEE Trans. Geosci. Remote Sens. 36, 1113-1126.

Goward, S., Masek, J., Williams, D., Irons, J. and Thompson, R.: 2001, The Landsat 7 mission- terrestrial research and applications for the 21st century, Remote Sens. Environ. 78, 3-12.

Gutman, G. and Ignatov, A.: 1998, The derivation of green vegetation fraction from NOAA/AVHRR data for use in numerical weather prediction models, 
Int. J. Remote Sens. 19, 1533-1543.

Havstad, K., Kustas, W., Rango, A., Ritchie, J. and Schmugge, T.: 2000, Jornada experimental range: a unique arid land location for experiments to validate satellite systems, Remote Sens. Environ. 74(1), 13-25.

Hook, S., Dmochowski, J., Howard, K., Rowan, L., Karlstrom, K. and Stock, J.: 2005, Mapping variations in weight percent silica measured from multispectral thermal infrared imagery- examples from the Hiller Mountains, Nevada, USA and Tres Virgenes-La Reforma, Baja California Sur, Mexico, Remote Sens. Environ. 95, 273-289.

Hook, S. J., Gabell, A., Green, A. and Kealy, P.: 1992, A comparison of techniques for extracting emissivity information form thermal infrared data for geologic studies, Remote Sens. Environ. 42, 123-135.

Hook, S. J., Meyers, J. J., Thome, K. J., Fitzgerald, M. and Kahle, A. B.: 2001, The MODIS/ASTER airborne simulator (MASTER)- a new instrument for earth science studies, Remote Sens. Environ. 76, 93-102.

Humes, K., Kustas, W., Moran, M., Nichols, W. and Weltz, M.: 1994, Variability of emissivity and surface temperature over a sparsely vegetated surface, Water Resour. Res. 30(5), 1299-1310.

Jacob, F., Petitcolin, F., Schmugge, T., Vermote, E., Ogawa, K. and French, A.: 2004, Comparison of land surface emissivity and radiometric temperature from MODIS and ASTER sensors, Remote Sensing of Environment $83,1-18$.

Jacob, F., Schmugge, T., Olioso, A., Courault, D., French, A., Ogawa, K., Petitcolin, F., Chehbouni, G., Pinheiro, A. and Privette, J.: 2007, Modeling and inversion in thermal infrared remote sensing over vegetated land surfaces, in press, Springer.

Jet Propulsion Laboratory: 2001, ASTER spectral library. 
http://speclib.jpl.nasa.gov.

Jiang, Z., Huete, A. R., Chen, J., Chen, Y., Li, J., Yan, G. and Zhang, X.: 2006, Analysis of NDVI and scaled difference vegetation index retrievals of vegetation fraction, Remote Sens. Environ. 101(3), 366-378.

Jiménez-Muñoz, J. C., Sobrino, J. A., Gillespie, A., Sabol, D. and Gustafson, W. T.: 2006, Improved land surface emissivities over agricultural areas using ASTER NDVI, Remote Sens. Environ. 103, 474-487.

Justice, C., Holben, B. and Gwynne, M.: 1986, Monitoring East African vegetation using AVHRR data, Int. J. Remote Sens. 7(11), 1453-1474.

Justice, C. and Townshend, J.: 2002, Special issue on the moderate resolution imaging spectroradiometer (MODIS): a new generation of land surface monitoring, Remote Sens. Environ. 83(1-2), 1-2.

Justice, C., Vermote, E., Townshend, J., Defries, R., Roy, D., Hall, D., Salomonson, V., Privette, J., Riggs, G., Strahler, A., Lucht, W., Myneni, R., Knyazikhin, Y., Running, S., Nemani, R., Wan, Z., Huete, A., Leeuwen, W., Wolfe, R., Giglio, L., Muller, J.-P., Lewis, P. and Barnsley, M.: 1998, The MODerate Imaging Spectroradiometer (MODIS): land remote sensing for global change research, IEEE Trans. Geosci. Remote Sens. 36, 1228-1249.

Kahle, A. B. and Alley, R. E.: 1992, Separation of temperature and emittance in remotely sensed radiance measurements, Remote Sens. Environ. 42, 107111.

Kahle, A., Madura, D. and Soha, J.: 1980, Middle infrared multispectral aircraft scanner data: analysis for geologic applications, Applied Optics 19, 2279-2290.

Li, Y., Chen, J., Gong, P. and Yue, T.: 2005, Study on land cover change detection method based on NDVI time series datasets: change detection indexes design, Journal of Basic Science and Engineering 13(3), 261-275. 
Li, Z.-L., Becker, F., Stoll, M. and Wan, Z.: 1999, Evaluation of six methods for extracting relative emissivity spectra from thermal infrared images, Agric. For. Meteorol. 69, 197-214.

Matsunaga, T.: 1994, A temperature-emissivity separation method using an empirical relationship between the mean, the maximum, and the minimum of the thermal emissivity spectrum, J. Remote Sens. Soc. Japan 14(2), 230241. in Japanese with English abstract.

Menenti, M., Jia, L. and Bastiaanssen, W.: 2005, Energy and water flow through the soil-vegetation-atmosphere system: the fiction of measurements and the reality of models, in R. Feddes, G. Rooij and J. van Dam (eds), Papers for the Frontis workshop on unsaturated-zone modeling: progress, challenges and applications, Wageningen, The Netherlands 3-5 October 2004, Springer, pp. 211-229.

Momeni, M. and Saradjian, M.: 2007, Evaluating NDVI-based emissivities of MODIS bands 31 and 32 using emissivities derived by Day/Night LST algorithm, Remote Sens. Environ. 106(2), 190-198.

Mushkin, A., Balick, L. K. and Gillespie, A. R.: 2005, Extending surface temperature and emissivity retrieval to the mid-infrared $(3-5 \mu \mathrm{m})$ using the Multispectral Thermal Imager (MTI), Remote Sens. Environ. 98, 141-151.

Nerry, F., Petitcolin, F. and Stoll, M.: 1998, Bidirectional reflectivity in AVHRR channel 3: application to a region in northern Africa, Remote Sens. Environ. 66, 298-316.

Norman, J., Divakarla, M. and Goel, N.: 1995, Algorithms for extracting information from remote thermal-IR observations of the earth's surface, Remote Sens. Environ. 51, 157-168.

Norman, J. M. and Becker, F.: 1995, Terminology in thermal infrared remote sensing of natural surfaces, Agric. For. Meteorol. 77, 153-166. 
Palluconi, F., Kahle, A., Hoover, G. and Conel, J.: 1990, The spectral emissivity of prairie and pasture grasses at Konza prairie, Kansas, Proc. Amer. Meteorol. Soc. Symp. on the First ISLSCP Field Experiment (FIFE) Feb. 7-9, Amer. Meteorol. Soc., 45 Beacon St., Boston, MA USA.

Pelgrum, H.: 2000, Length-scale analysis of surface albedo, temperature, and normalized difference vegetation index in desert grassland, Water Resources Research 36(7), 1757-1765.

Petitcolin, F. and Vermote, E.: 2002, Land surface reflectance, emissivity and temperature from MODIS middle and thermal infrared data, Remote Sens. Environ. 83(1-2), 112-134.

Qi, J., Chehbouni, A., Huete, A., Kerr, Y. and Sorooshian, S.: 1994, A modified soil adjusted vegetation index, Remote Sens. Environ. 48, 119-126.

R Development Core Team: 2006, R: A Language and Environment for Statistical Computing, R Foundation for Statistical Computing, Vienna, Austria. ISBN 3-900051-07-0.

URL: http://www.R-project.org

Rango, A., L.Huenneke, Buonopane, M., Herrick, J. and Havstad, K.: 2005, Using historic data to assess effectiveness of shrub removal in southern New Mexico, J. Arid Environ. 62, 75-91.

Rowan, L. and Mars, J.: 2003, Lithologic mapping in the Mountain Pass, California area using Advanced Spaceborne Thermal Emission and Reflection Radiometer (ASTER) data, Remote Sens. Environ. 84, 350-366.

Rowan, L., Mars, J. and Simpson, C.: 2005, Lithologic mapping of the Mordor, NT, Australia ultramafic complex by using the Advanced Spaceborne Thermal Emission and Reflection Radiometer (ASTER), Remote Sens. Environ. 99(1-2), 105-126.

Salisbury, J. W. and D'Aria, D. M.: 1992, Emissivity of terrestrial materials 


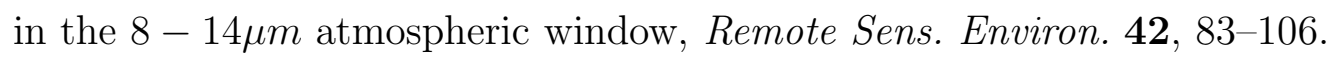

Salisbury, J. W. and Eastes, J. W.: 1985, The effect of particle size and porosity on spectral contrast in the mid-infrared, Icarus $\mathbf{6 4}, 586-588$.

Snyder, K. and Tartowski, S.: 2006, Multi-scale temporal variation in water availability: implications for vegetation dynamics in arid and semi-arid ecosystems, J. Arid Environ. 65, 219-234.

Sobrino, J., dn J. El Kharraz, G. C., Gomez, M., Guemouria, N., Hasager, C., Olioso, A. and Rahman, A.: 2001, WATERMED-Water use efficiency in natural vegetation and agricultural areas by remote sensing in the Mediterranean Basin, Arid regions monitored by satellites from observing to modelling for sustainable management, Marrakech, Maroc, 12-15 November 2001.

Su, Z. B.: 2000, Remote sensing of land use and vegetation for mesoscale hydrological studies, Int. J. Remote Sens. 21(2), 213-233.

Sutherland, R. and Bartholic, J.: 1977, Significance of vegetation in interpreting thermal radiation from a terrestrial surface, Journal of Applied Meteorology 16, 759-763.

Telesca, L. and Lasaponara, R.: 2006, Quantifying intra-annual persistent behaviour in SPOT-VEGETATION NDVI data for Mediterranean ecosystems of southern Italy, Remote Sens. Environ. 101, 95-103.

Tonooka, H.: 2001, An atmospheric correction algorithm for thermal infrared multispectral data over land- a water-vapor scaling method, IEEE Trans. Geosci. Remote Sens. 39(3), 682-692.

Tonooka, H., Palluconi, F., Hook, S. and Matsunaga, T.: 2005, Vicarious calibration of ASTER thermal infrared bands, IEEE Trans. Geosci. Remote Sens. 43, 2733-2746.

Tonooka, H., Sakuma, F., Kudoh, M. and Iwafune, K.: 2003, ASTER/TIR 
calibration status and user-based recalibration, Proceedings of SPIE, Vol. 5234, SPIE, pp. 191-201.

Valor, E. and Caselles, V.: 1996, Mapping land surface emissivity from NDVI: application to European, African, and South American areas, Remote Sens. Environ. 57, 167-184.

Van de Griend, A. and Owe, M.: 1993, On the relationship between thermal emissivity and the normalized difference vegetation index for natural surfaces, Int. J. Remote Sens. 14(6), 1119-1131.

Vermote, E. F., Tanré, D., Deuzé, J. L., Herman, M. and Morcrette, J.-J.: 1997, Second simulation of the satellite signal in the solar spectrum, 6S: and overview, IEEE Trans. Geosci. Remote Sens. 35(3), 675-686.

Wardlow, B. D., Egbert, S. L. and Kastens, J. H.: 2007, Analysis of timeseries MODIS $250 \mathrm{~m}$ vegetation index data for crop classification in the u.s. central great plains, Remote Sens. Environ. 108(3), 290-310.

Watson, K.: 1992, Two-temperature method for measuring emissivity, Remote Sens. Environ. 42, 117-121.

Yamaguchi, Y., Kahle, A., Tsu, H., Kawakami, T. and Pniel, M.: 1998, Overview of Advanced Space-borne Thermal Emission and Reflection Radiometer (ASTER), IEEE Transactions on Geoscience and Remote Sensing 36, 1282-1289.

Zhang, H.-Y. and Smith, W.: 1990, The spectral variation of surface emissivity within the $8-12 \mu \mathrm{m}$ "window", Proceedings of the Fall American Geophys. Union Meeting, American Geophysical Union, 2000 Florida Ave., NW, Washington, DC 20009 USA. 


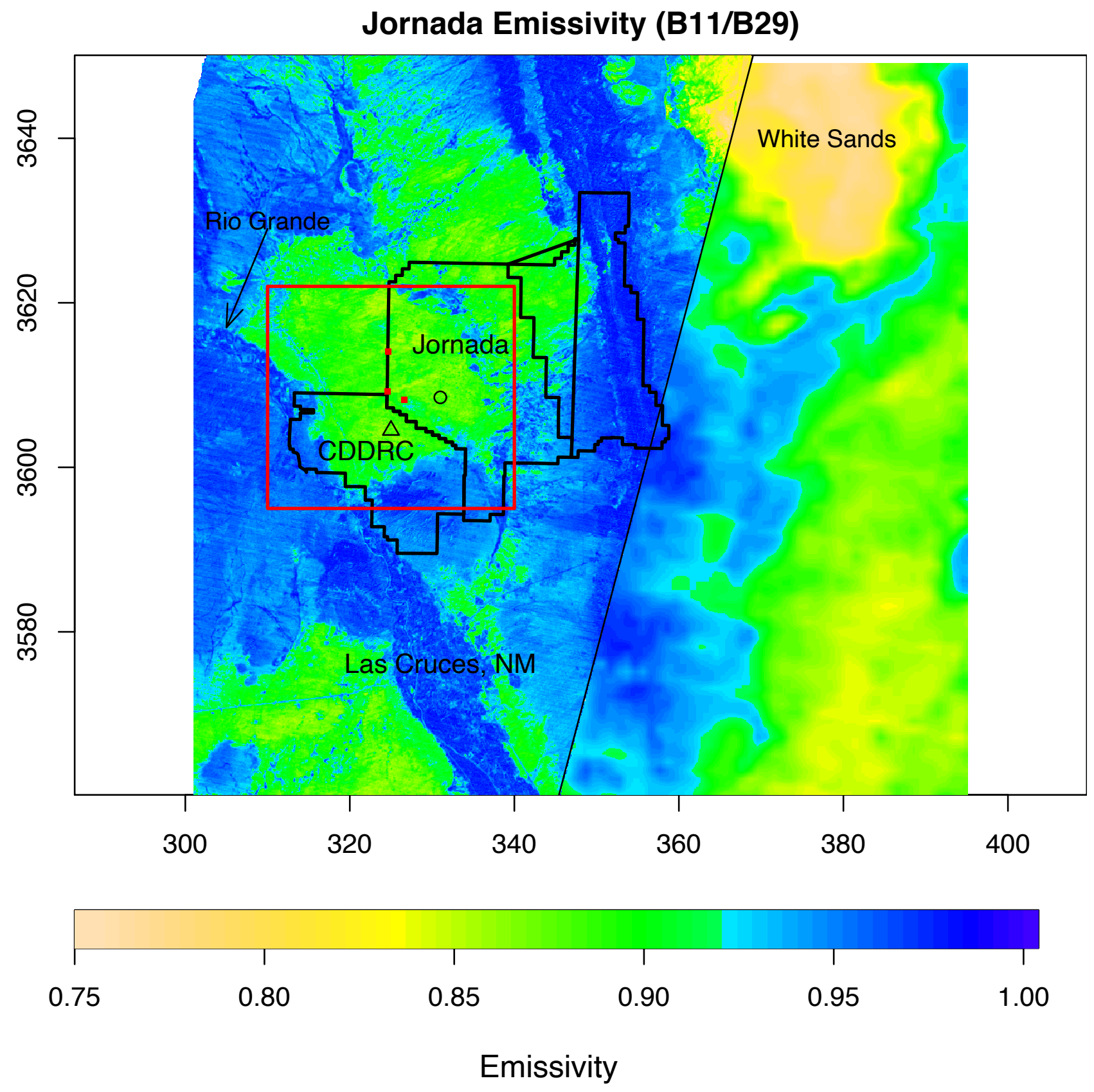


Figures_2

\section{Emissivity Response and Spectra}

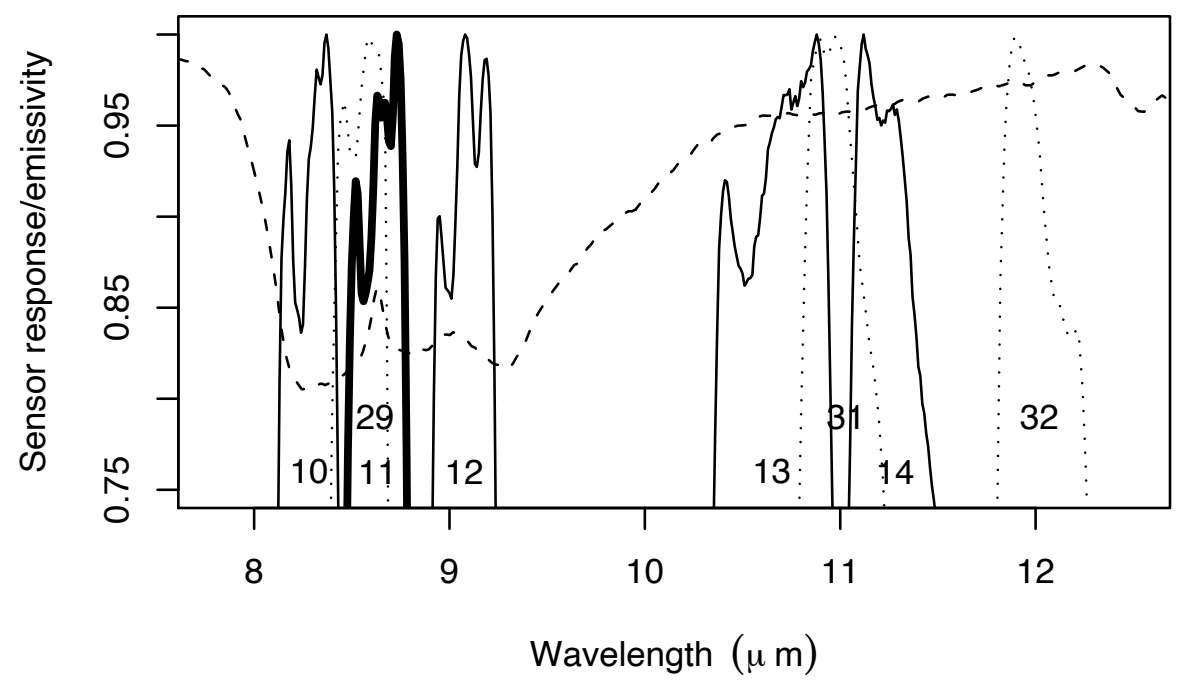




\section{EPZ 2001-2003}

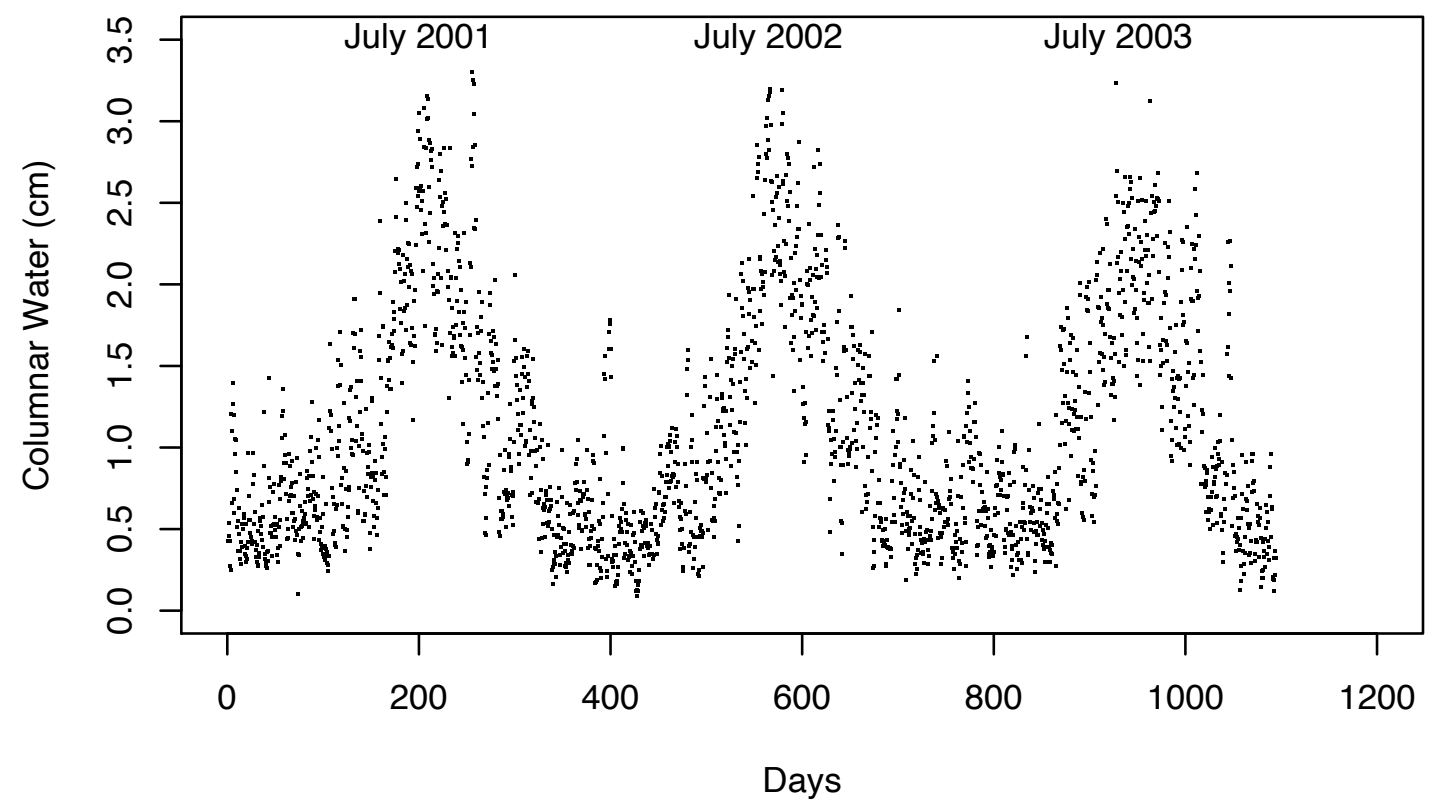



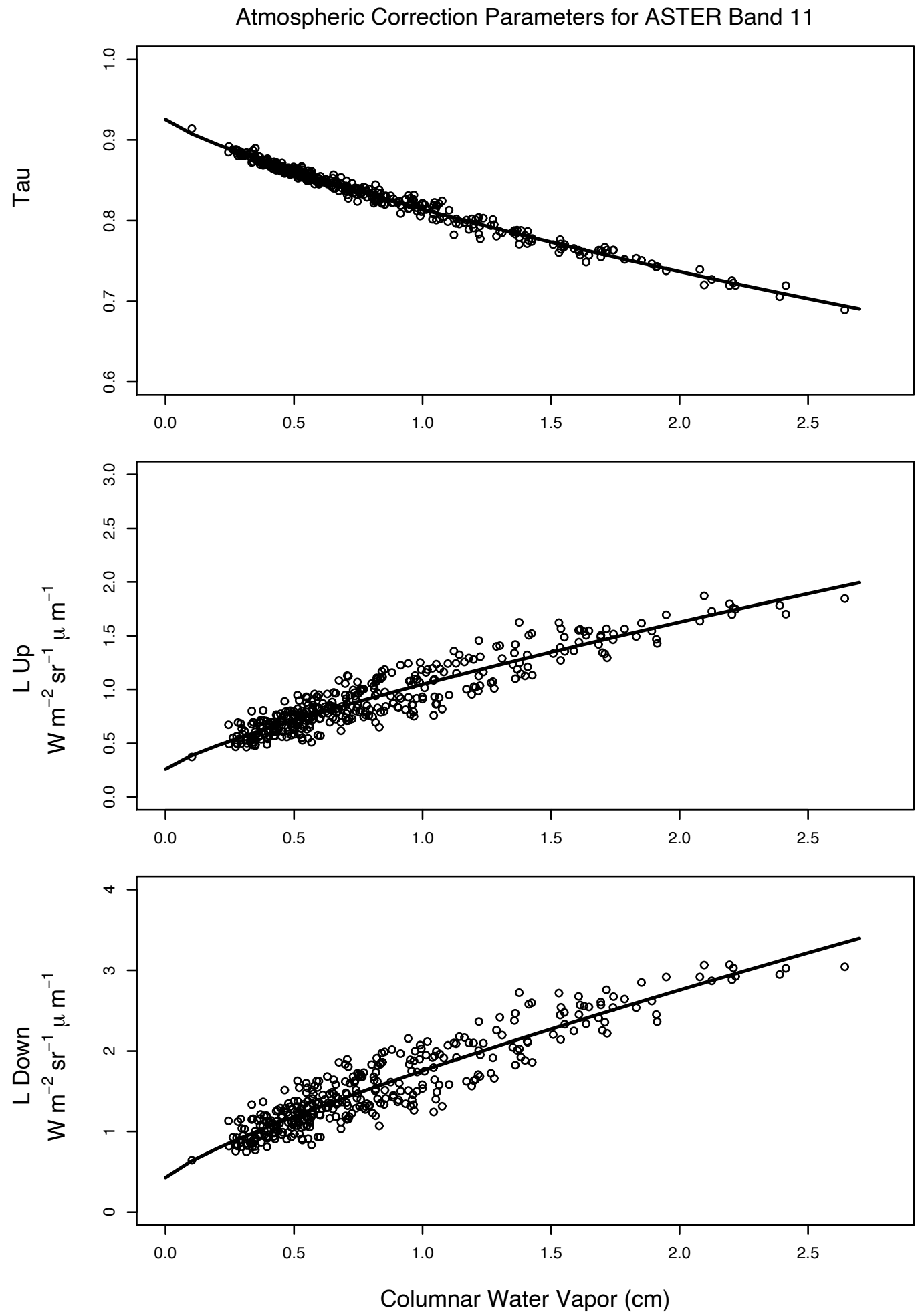
Emissivity Uncertainty Simulation

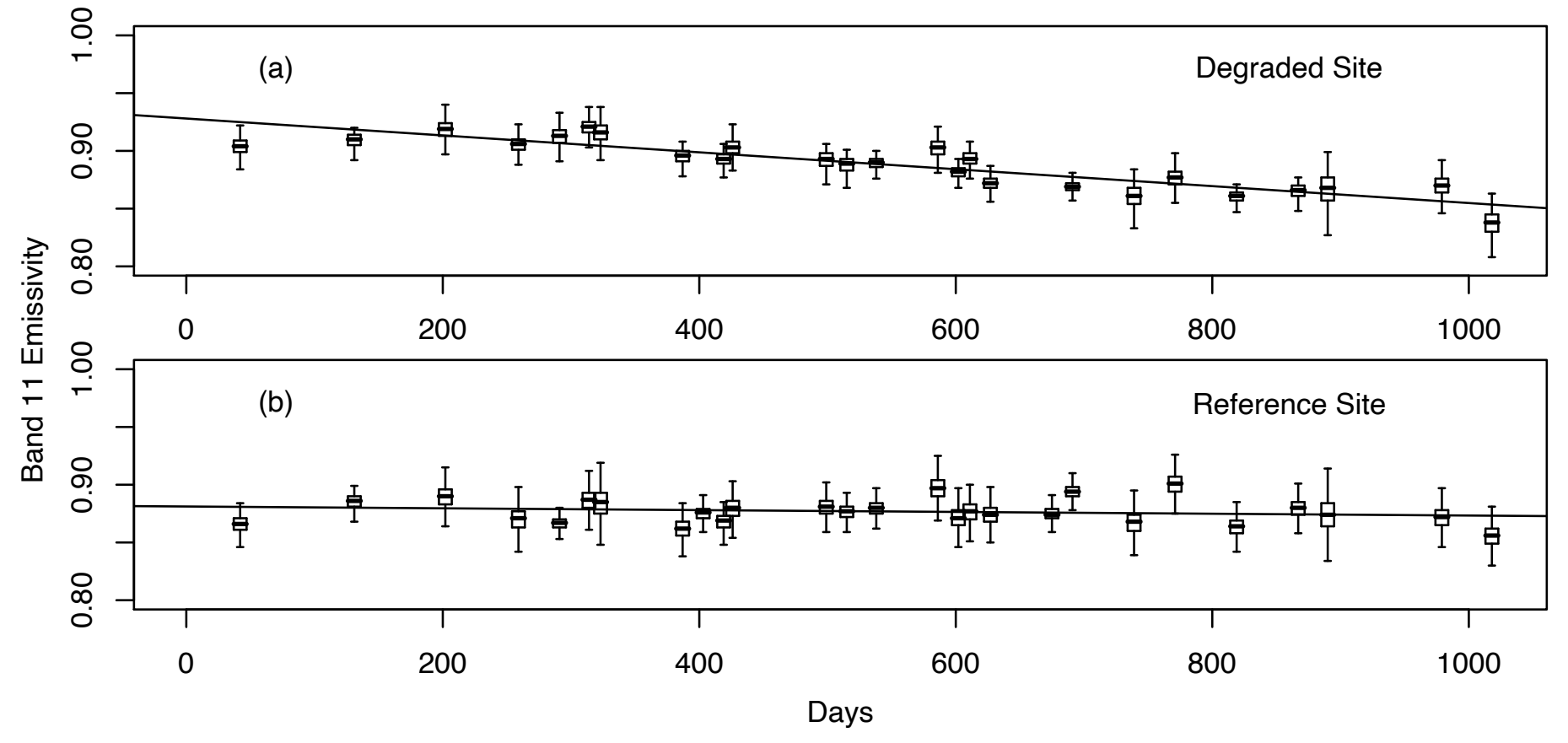




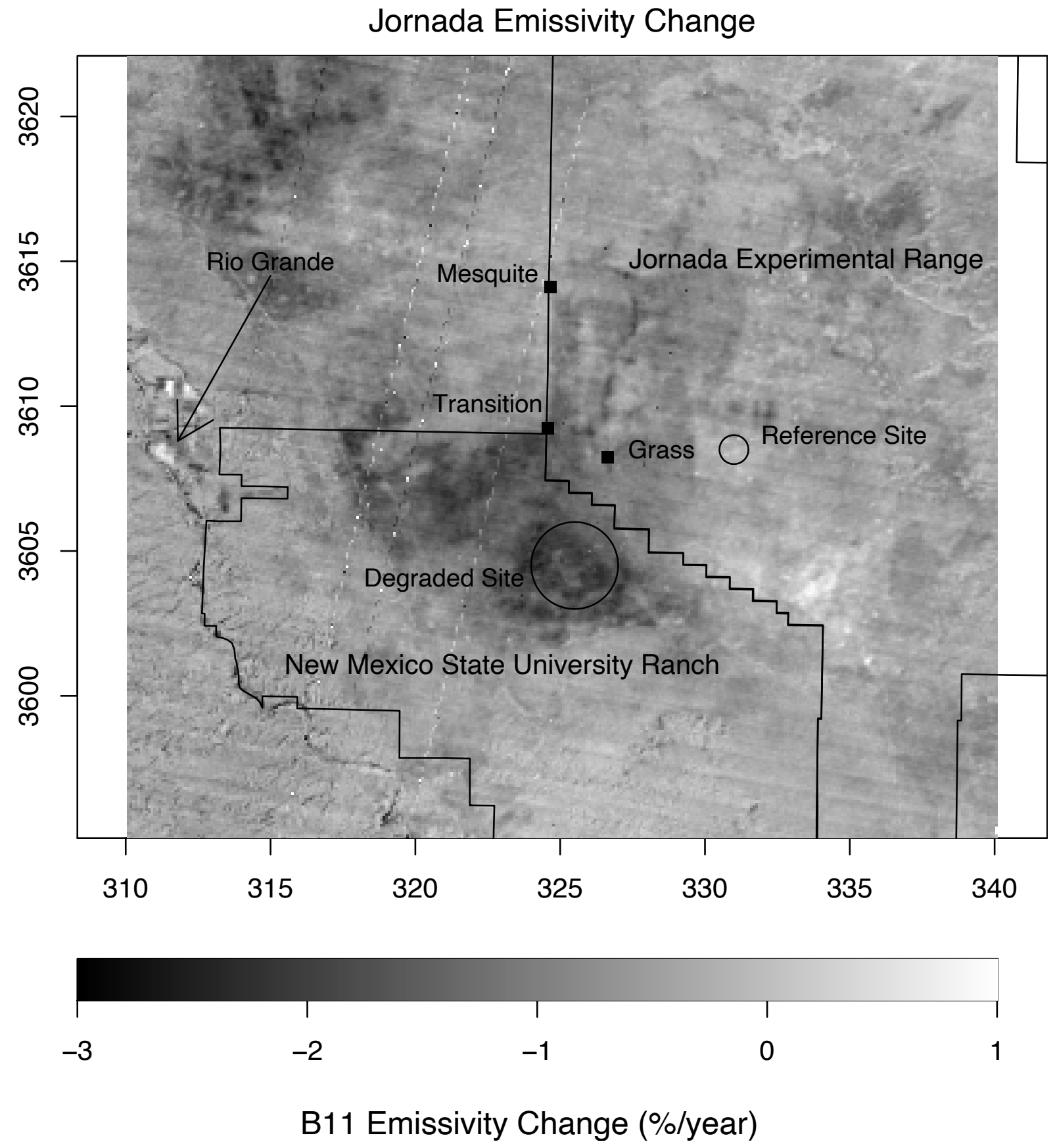




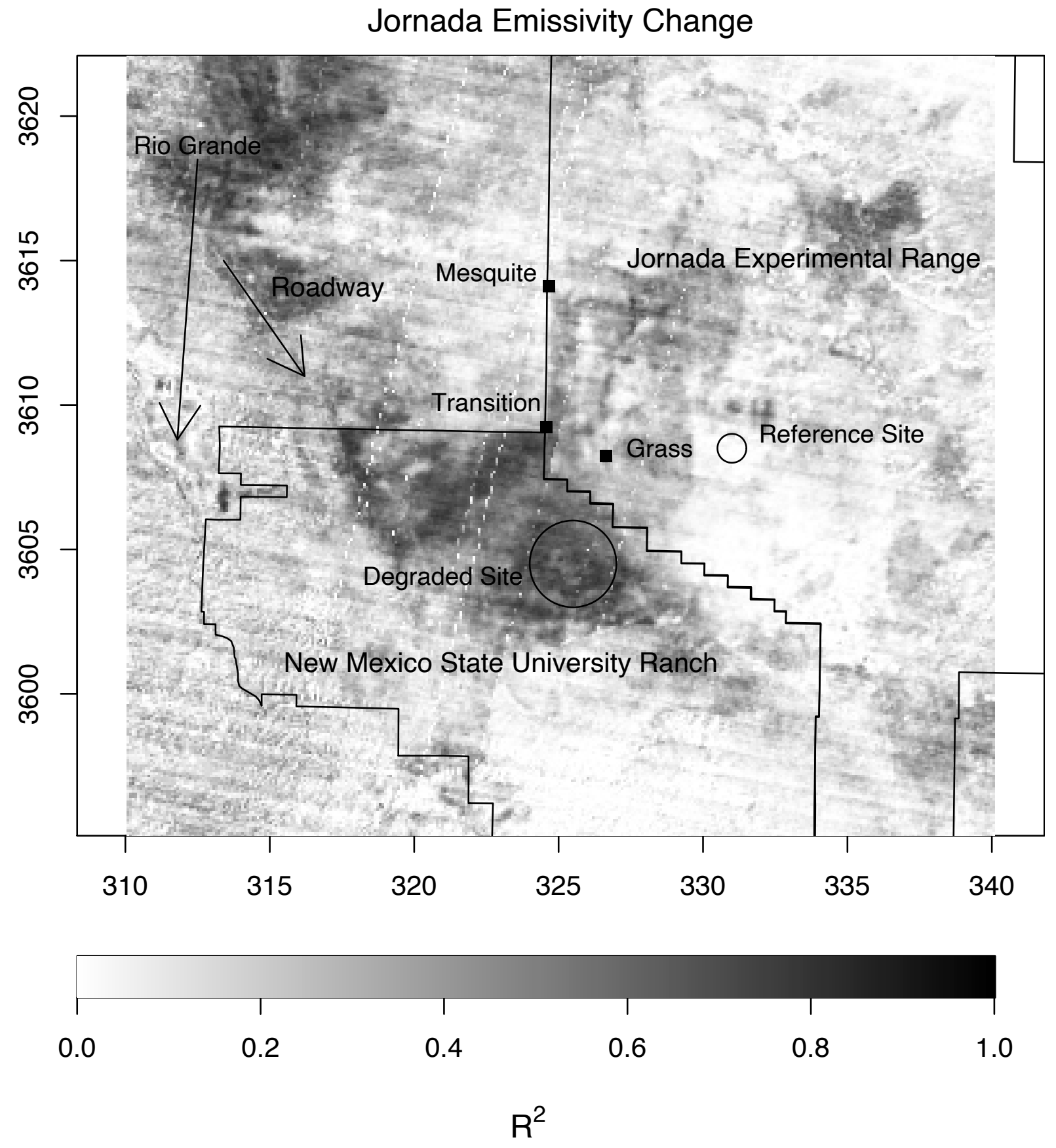


Band 11 Emissivity
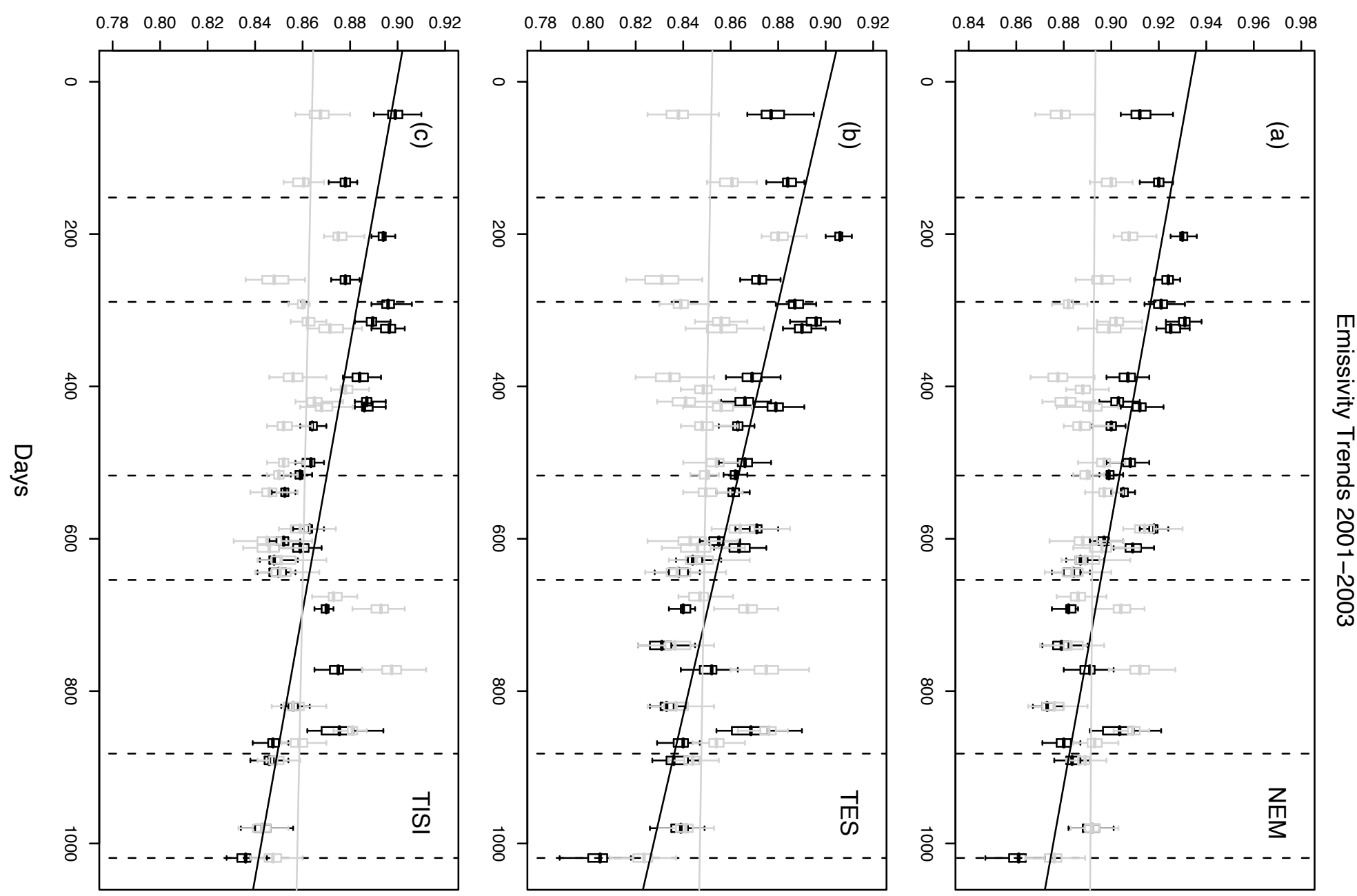

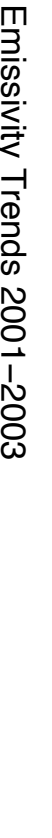




\section{Emissivity Trend at White Sands}

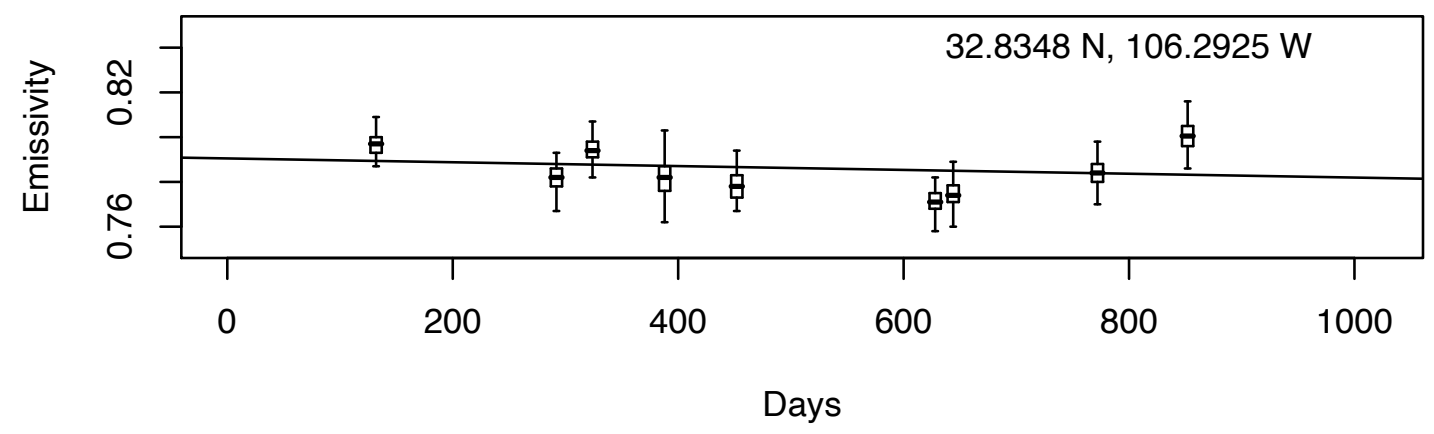




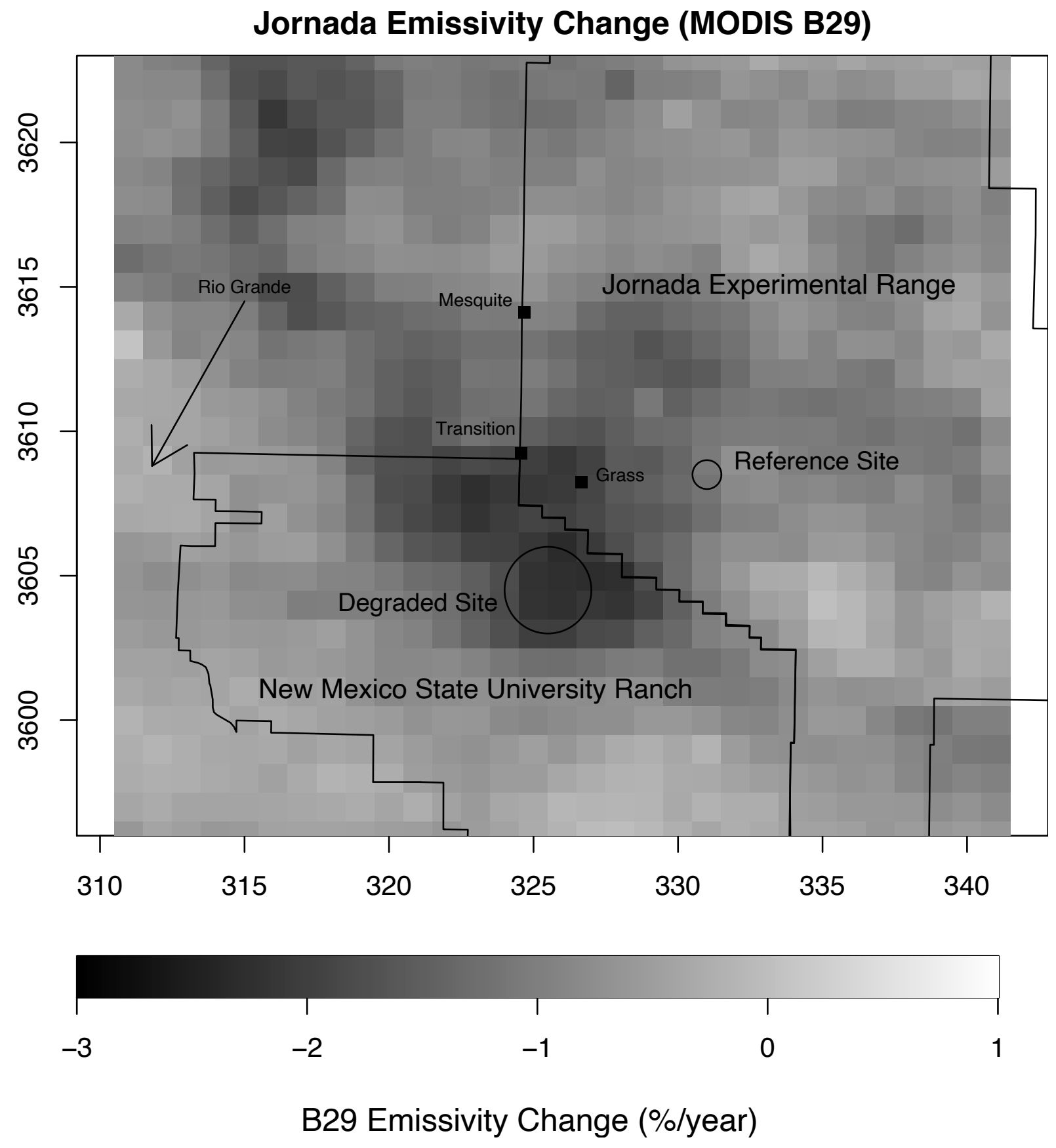


NDVI Trends 2001-2003
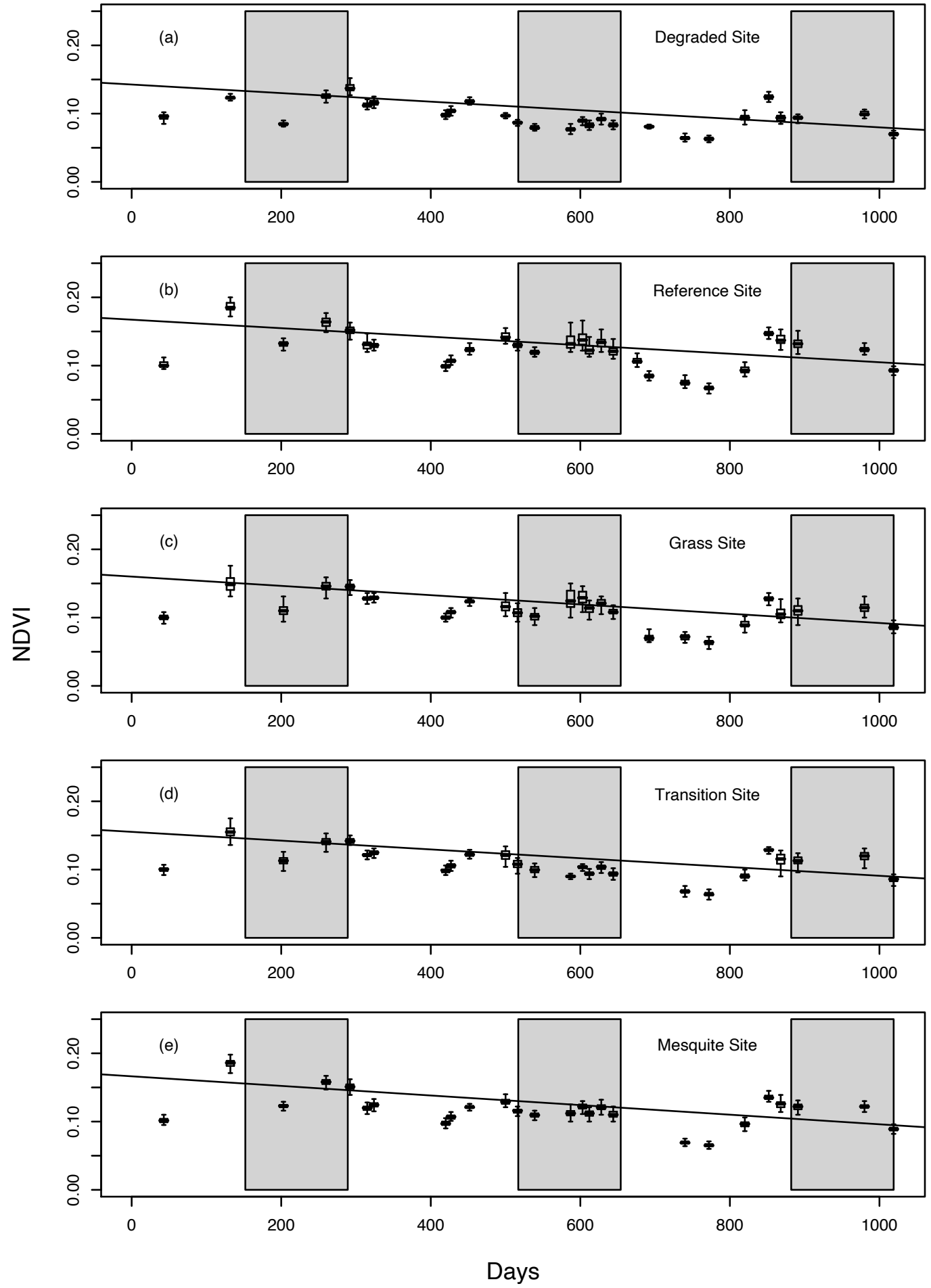
Figures_12

Jornada Sites

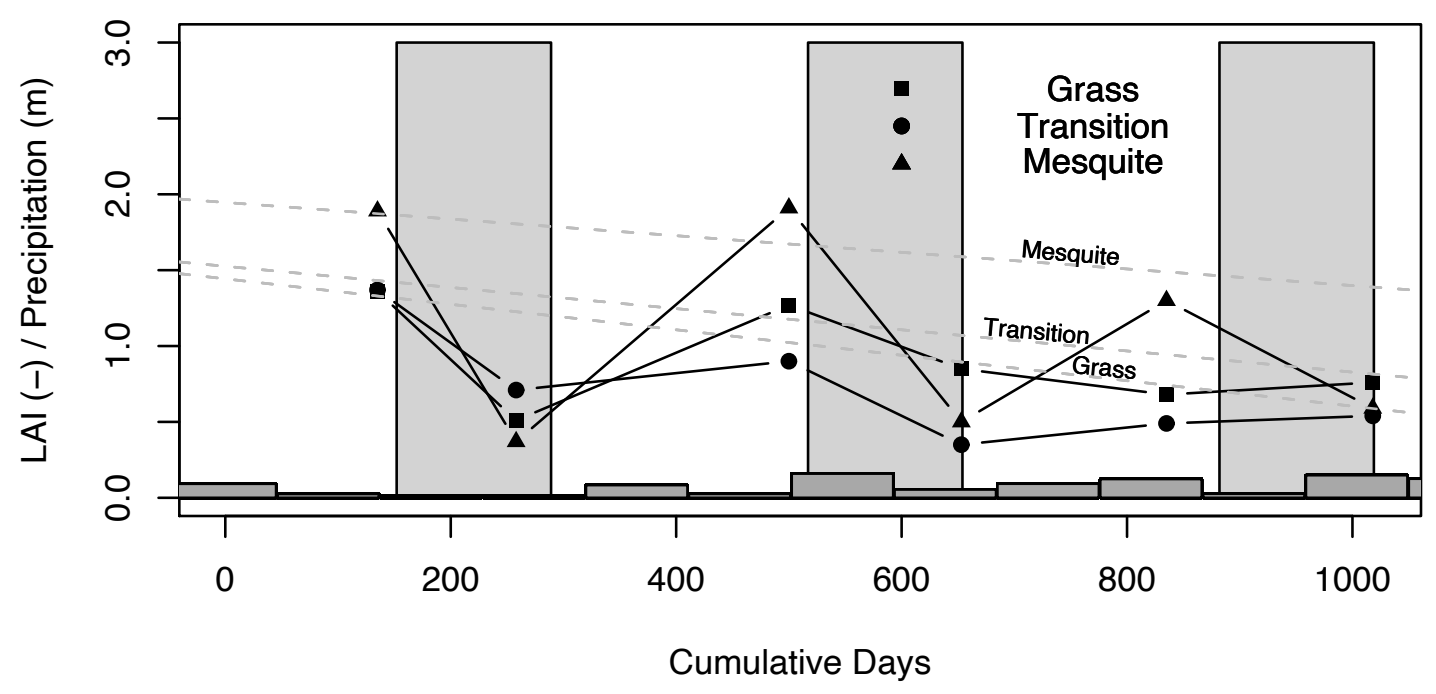



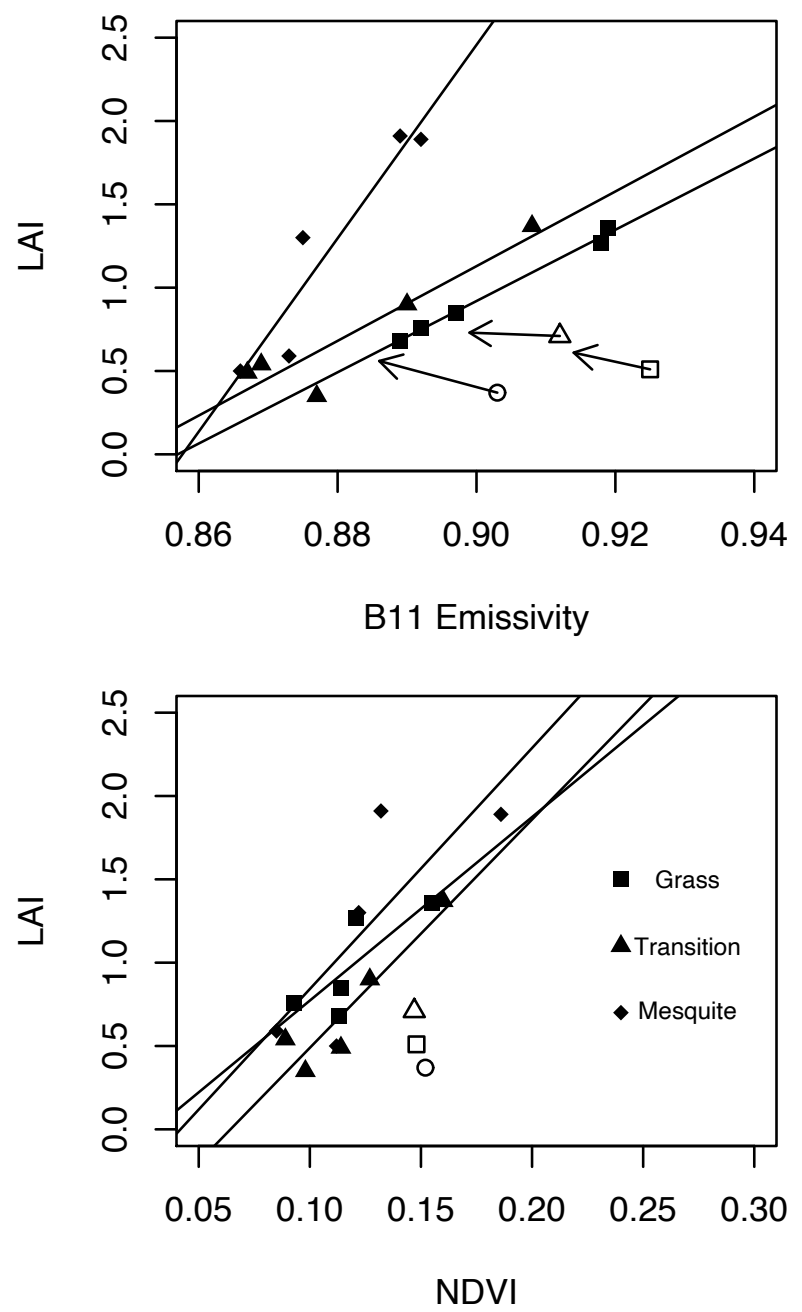
ASTER Band 11 Emissivities vs. NDVI
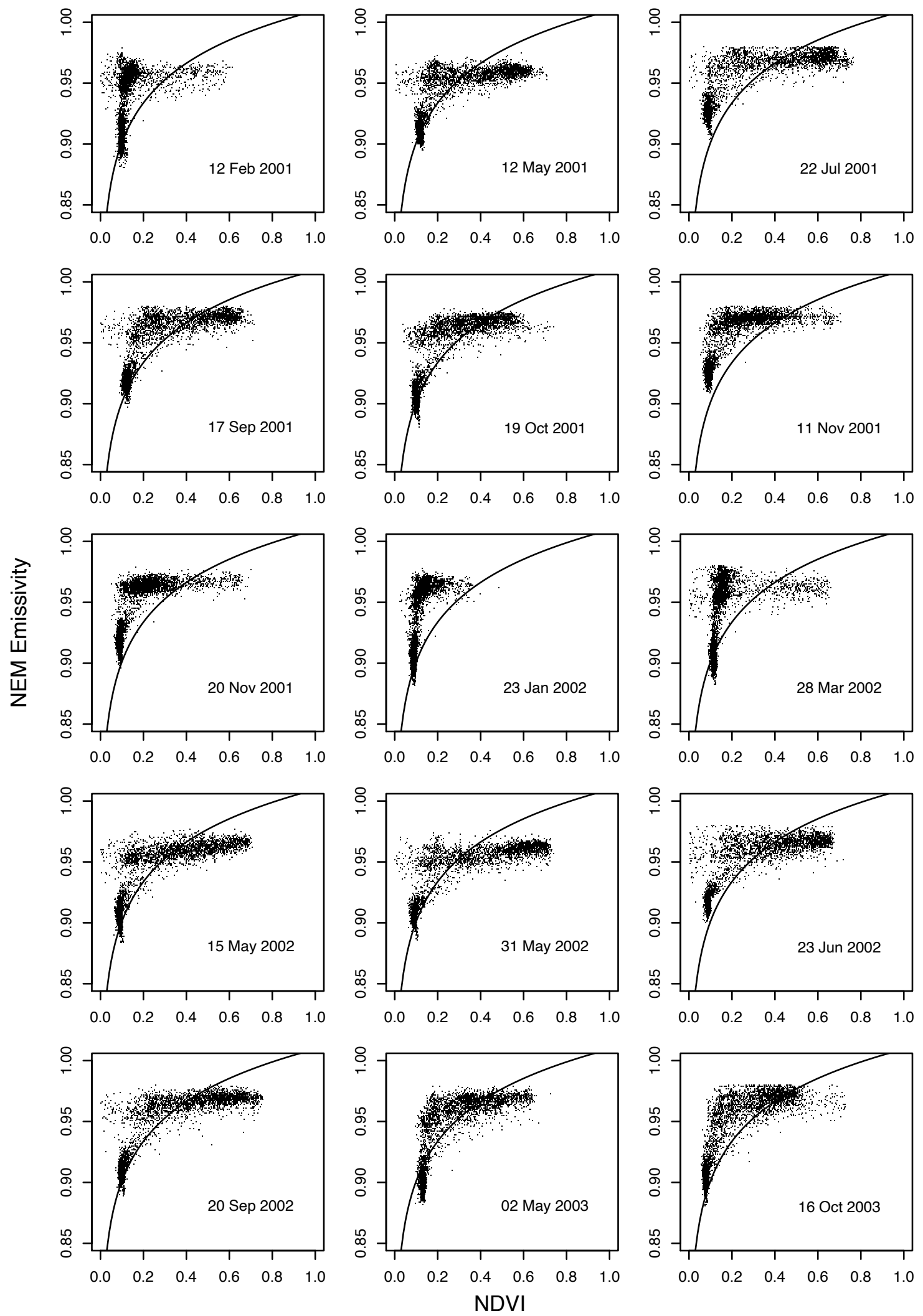